\title{
Molecular antagonism between X-chromosome and autosome signals determines nematode sex
}

\author{
Behnom Farboud, ${ }^{1}$ Paola Nix, ${ }^{1,2}$ Margaret M. Jow, ${ }^{1,3}$ John M. Gladden, ${ }^{1,4}$ and Barbara J. Meyer ${ }^{1,5}$ \\ ${ }^{1}$ Howard Hughes Medical Institute, Department of Molecular and Cell Biology, University of California at Berkeley, Berkeley, \\ California 94720, USA
}

\begin{abstract}
Sex is determined in Caenorhabditis elegans by the ratio of $\mathrm{X}$ chromosomes to the sets of autosomes, the X:A signal. A set of genes called X signal elements (XSEs) communicates X-chromosome dose by repressing the masculinizing sex determination switch gene xol-1 (XO lethal) in a dose-dependent manner. xol-1 is active in 1X:2A embryos (males) but repressed in 2X:2A embryos (hermaphrodites). Here we showed that the autosome dose is communicated by a set of autosomal signal elements (ASEs) that act in a cumulative, dose-dependent manner to counter XSEs by stimulating xol-1 transcription. We identified new ASEs and explored the biochemical basis by which ASEs antagonize XSEs to determine sex. Multiple antagonistic molecular interactions carried out on a single promoter explain how different X:A values elicit different sexual fates. XSEs (nuclear receptors and homeodomain proteins) and ASEs (T-box and zinc finger proteins) bind directly to several sites on xol-1 to counteract each other's activities and thereby regulate xol-1 transcription. Disrupting ASE- and XSE-binding sites in vivo recapitulated the misregulation of xol-1 transcription caused by disrupting cognate signal element genes. XSE- and ASE-binding sites are distinct and nonoverlapping, suggesting that direct competition for xol-1 binding is not how XSEs counter ASEs. Instead, XSEs likely antagonize ASEs by recruiting cofactors with reciprocal activities that induce opposite transcriptional states. Most ASE- and XSE-binding sites overlap xol-1's -1 nucleosome, which carries activating chromatin marks only when xol-1 is turned on. Coactivators and corepressors tethered by proteins similar to ASEs and XSEs are known to deposit and remove such marks. The concept of a sex signal comprising competing XSEs and ASEs arose as a theory for fruit flies a century ago. Ironically, while the recent work of others showed that the fly sex signal does not fit this simple paradigm, our work shows that the worm signal does.
\end{abstract}

[Keywords: sex determination; haploinsufficiency; dose-sensitive signals; dosage compensation; nuclear hormone receptor; T-box protein]

Supplemental material is available for this article.

Received March 3, 2013; revised version accepted April 15, 2013.

Dose-dependent signals play essential roles in cell fate decisions during development. Small differences in the concentrations of key regulatory molecules are translated into dramatically different developmental fates (Herskowitz 1989; Perry et al. 2009; Shilo et al. 2013). A prime example is sex determination (Bull 1983; Charlesworth and Mank 2010). In many species, sex is determined by a chromosome-counting mechanism that tallies the number of $\mathrm{X}$ chromosomes relative to the ploidy,

Present addresses: ${ }^{2}$ Department of Biology, University of Utah, Salt Lake City, UT 84112, USA; ${ }^{3}$ Department of Biology, San Francisco State University, San Francisco, CA 94132, USA; ${ }^{4}$ Bioengineering and Biomass Science, Conversion Technology Department, Sandia National Laboratories, Livermore, CA 94551, USA.

${ }^{5}$ Corresponding author

E-mail bjmeyer@berkeley.edu

Article published online ahead of print. Article and publication date are online at http://www.genesdev.org/cgi/doi/10.1101/gad.217026.113. the sets of autosomes. The molecular strategies for such $\mathrm{X}$ :A-counting mechanisms have been difficult to dissect. For both the nematode Caenorhabditis elegans and the fruit fly Drosophila melanogaster, an X:A signal of 0.5 (1X:2A) elicits male fate, while a signal of 1.0 (2X:2A) elicits female (or hermaphrodite) fate (Bridges 1921; Nigon 1951). Worms discriminate with high fidelity between even smaller differences in the X:A signal: $2 \mathrm{X}: 3 \mathrm{~A}(0.67)$ embryos develop into fertile males, while 3X:4A (0.75) embryos develop into fertile hermaphrodites (Madl and Herman 1979). Neither the components of the worm sex signal nor its mechanism for determining sex are well understood. Particularly elusive has been how $\mathrm{X}$ and autosomal signals oppose one another to communicate the relative doses of $\mathrm{X}$ chromosomes and autosomes.

The initial concept that sex can be determined through an X:A-sensing mechanism emerged from Calvin Bridges' (Bridges 1921) extensive analysis of fly sexual fates induced 
by different X:A values. In 1921, he proposed that the fly sex signal is composed of a set of feminizing genes on $\mathrm{X}$ and an antagonistic set of masculinizing genes on autosomes. Sex would be determined by the ratio of these opposing factors. His hypothesis met wide acceptance and was presented in textbooks as fact without validation by the discovery of such antagonistic sex-determining genes. Ironically, detailed molecular analysis conducted decades later showed that the fly X:A sex determination signal does not fit this elegant textbook paradigm (Erickson and Quintero 2007), but we show here that the worm signal does.

In flies, a set of feminizing genes on $\mathrm{X}$ called $\mathrm{X}$ signal elements (XSEs) communicates X-chromosome number (Cline 1988; Erickson and Cline 1991, 1993; Sefton et al. 2000; Salz and Erickson 2010), but ploidy appears not to be signaled by a corresponding set of masculinizing autosomal genes (Erickson and Quintero 2007). Only a single autosomal signal element (ASE) has been identified through extensive genetic screens (Barbash and Cline 1995). That ASE influences sex determination only weakly and is thought to function relatively late to fine-tune the counting process. The effect of ploidy in this dose-sensitive process was recently shown to be indirect (Erickson and Quintero 2007).

In C. elegans, $\mathrm{X}$-chromosome number is also communicated by a set of trans-acting XSEs encoded on X chromosomes (Fig. 1A; Akerib and Meyer 1994; Hodgkin et al. 1994; Nicoll et al. 1997; Carmi et al. 1998; Gladden and Meyer 2007; Gladden et al. 2007; Meyer 2010). XSEs act in a cumulative, dose-dependent manner to repress the masculinizing sex determination switch gene called xol-1 (XO lethal) in 2X:2A embryos. xol-1 encodes a GHMP kinase family member that induces the male fate when active and permits the hermaphrodite fate when inactive (Miller et al. 1988; Rhind et al. 1995; Luz et al. 2003). xol-1 also controls the level of X-linked gene expression, and hence viability, by regulating the process of X-chromosome dosage compensation (Miller et al. 1988; Chuang et al. 1994; Rhind et al. 1995; Dawes et al. 1999). xol-1 coordinately regulates both sex determination and dosage compensation by negatively regulating the feminizing switch gene $s d c-2$ (sex determination and dosage compensation), which triggers assembly of all dosage compensation complex (DCC) subunits onto both X chromosomes of XX embryos to reduce X-linked gene expression by half (Dawes et al. 1999; Pferdehirt et al. 2011). sdc-2 also induces hermaphrodite sexual differentiation by repressing the autosomal male sex-determining gene her-1. Inappropriate repression of xol-1 in 1X:2A embryos or inappropriate activation of xol-1 in 2X:2A embryos causes embryonic lethality due to misregulation of the DCC and hence incorrect levels of X-chromosome gene expression.

XSEs were discovered through genetic schemes that identified suppressors of the lethal effects caused by xol-1 misregulation (Akerib and Meyer 1994; Hodgkin et al. 1994; Nicoll et al. 1997; Carmi et al. 1998; Gladden and Meyer 2007). XSEs control xol-1 at two distinct levels: transcriptional repression via the nuclear receptor SEX-1 and the ONECUT homeodomain protein CEH-39 and post-transcriptional repression via the RNA-binding protein FOX-1 (Hodgkin et al. 1994; Nicoll et al. 1997; Carmi et al. 1998; Skipper et al. 1999; Gladden and Meyer 2007; Gladden et al. 2007). Disruption of SEX-1 causes extensive but incomplete XX-specific lethality, and simultaneous disruption of both SEX-1 and CEH-39 or SEX-1 and FOX-1 causes complete XX lethality due to derepression of xol-1. Disruption of either CEH-39 or FOX-1 alone has minimal effects on viability. Transcriptional repression is the predominant form of xol-1 regulation, but prior to our current study, it was not known whether SEX-1 and CEH-39 control xol-1 indirectly or through direct molecular interactions with cis-acting regulatory regions.

Our previous work showed that the autosomal signal includes a trans-acting ASE that counters XSEs in part to coordinately regulate both sex determination and dosage compensation by activating xol-1 (Fig. 1A; Powell et al. 2005). This ASE, called SEA-1 (signal element on autosome), was identified as a suppressor of the XX-specific lethality caused by loss of XSEs. SEA-1 is T-box transcription factor that acts in a dose-dependent manner to stimulate xol-1 transcription. Not known was whether SEA-1 acts directly on xol-1 to control its expression, how an ASE might antagonize XSEs, and whether worms, like flies, have only a single weak ASE and also use an ASEindependent mechanism to communicate ploidy.

In our current study to dissect the C. elegans sex determination signal and discover the molecular mechanisms by which small differences in the X:A signal elicit alternate sexual fates, we first conducted a genetic screen to identify additional ASEs and then explored the biochemical basis by which XSEs counter ASEs to determine sex. We show here that ploidy is communicated by multiple discrete ASEs, which function in a dose-dependent and cumulative manner to activate xol-1 transcription, consistent with Bridges' hypothesis for flies (Bridges 1921). We also show that XSEs engage in molecular rivalry with ASEs to overcome their activating effects, thereby translating the twofold difference in X-chromosome dose between the sexes into the high or low activity state of xol-1. Transcriptional activation of xol-1 by ASEs is direct. Two of the ASEs, SEA-1 and SEA-2 (a zinc finger protein), bind to multiple sites within xol-1. Transcriptional repression by XSEs is similarly direct: SEX-1 and CEH-39 also bind to numerous Xol-1 sites in vitro. Disrupting these ASEand XSE-binding sites in vivo recapitulates the deregulation of xol-1 expression caused by disrupting the corresponding signal element genes. The known XSE- and ASEbinding sites are distinct and nonoverlapping, suggesting that direct competition for binding to xol-1 is unlikely to be the mechanism by which XSEs oppose ASEs. Since other T-box proteins, nuclear receptors, and homeobox proteins tether coactivators or corepressors to specific binding sites (Asahara et al. 1999; Privalsky 2004; Murakami et al. 2005), the most plausible model is that XSEs and ASEs antagonize each other by recruiting cofactors with reciprocal activities that induce opposite transcriptional states. In summary, we demonstrated that multiple, antagonistic molecular interactions carried out on 
A

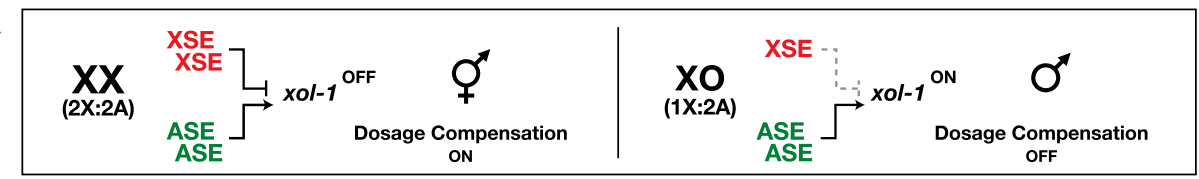

$\mathbf{B}$

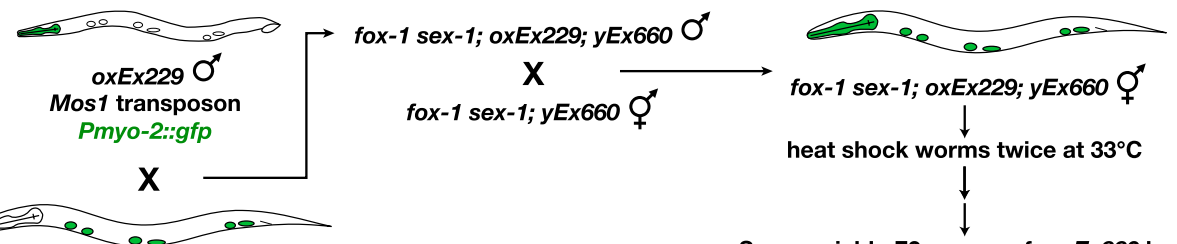

fox-1 sex-1; yEx660 O"

Mos1 transposase

Pdpy-30::sdc-2

Screen viable F2 progeny for $y E x 660$ loss

Punc-122::gfp

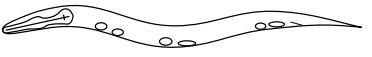

suppressor; fox-1 sex-1
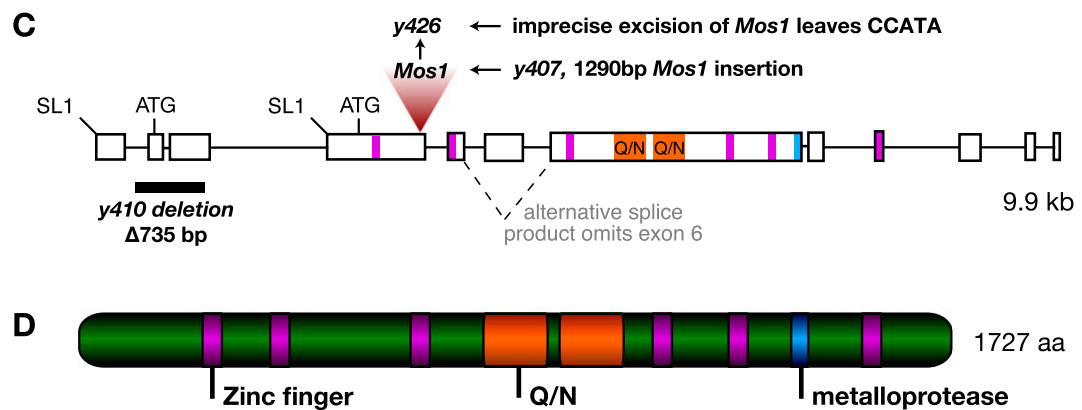

$\mathbf{E}$

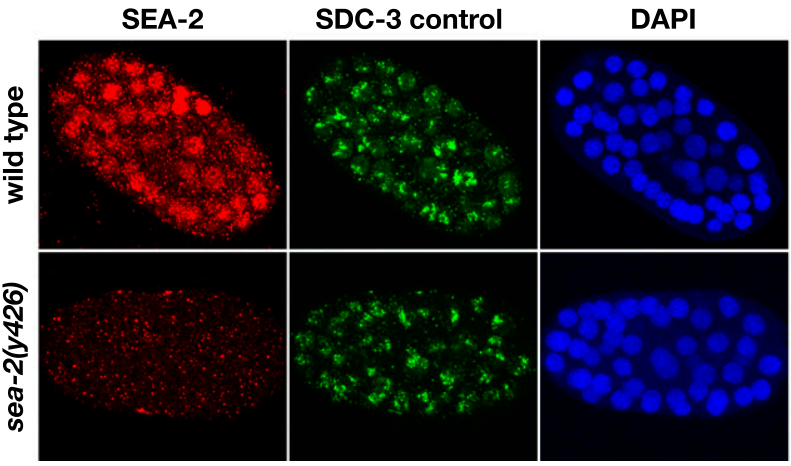

Figure 1. Identification of an ASE that encodes a zinc finger protein with $\mathrm{Q} / \mathrm{N}$ and metalloprotease repeats. $(A)$ Regulation of $x o l-1$ by XSEs and ASEs. In diploid XX embryos (2X:2A), the double dose of XSEs outcompetes the double dose of ASEs to repress Xol-1, thereby activating the hermaphrodite-specific gene $s d c-2$ and turning on dosage compensation and the hermaphrodite program of sexual differentiation. $s d c-2$ activates dosage compensation by triggering binding of the DCC to both X chromosomes, where it turns down $\mathrm{X}$-chromosome expression by about half. In diploid XO embryos (1X:2A), the single dose of XSEs fails to overcome the double dose of ASEs. Xol-1 remains active, represses $s d c-2$, turns on the male program of sexual differentiation, and precludes binding of the DCC to X. $(B)$ Genetic strategy for identifying ASEs. The Mos1 transposon strain used to obtain suppressors of the XX-specific lethality caused by disrupting two XSEs-fox-1 and sex-1-was made from crosses (shown) involving two initial strains. (1) A fox-1 sex-1 double-mutant strain carried an extrachromosomal array (yEx660) containing three transgenes: the Mos 1 transposase controlled by a heat-shock promoter (hsp-16-48::Mos 1 transposase); Pdpy-30::sdc-2, used to suppress the lethality of fox-1 sex-1 mutants; and Punc-122::gfp, a reporter for the array that causes coelomocytes to fluoresce green. (2) The strain carried an extrachromosomal array (oxEx229) bearing the Mos1 transposon and the reporter Pmyo-2::gfp, which causes the pharynx to fluoresce green. Mos1 was mobilized in the final strain (fox-1 sex-1; oxEx229; yEx660) by heat shock, and homozygous suppressors were identified among their F2 self progeny as viable hermaphrodites that lacked the yEx660 array. (C) Structure of the sea-2 gene showing intron-exon boundaries, locations, and molecular identity of sea-2 mutations; two SL1 TSL sites; an alternative splice junction; and locations of sequences encoding zinc fingers (magenta), Q/N repeats (orange), and the metalloprotease domain (blue). (D) Schematic of the SEA-2 protein showing locations of zinc fingers, Q/N repeats, and the metalloprotease domain. (E) Immunofluorescence images of wild-type and sea-2(y426)-null XX embryos stained with the DNA dye DAPI (blue) and antibodies to both SEA-2 (red) and the X-bound dosage compensation protein SDC-3 (green) used as a staining control. The diffuse nuclear SEA-2 signal was eliminated by the sea-2(y426)-null mutation, showing antibody specificity. 
a single promoter form the basis of the primary sex determination decision in C. elegans. This antagonism makes the sex determination process highly responsive to the relative dose of $\mathrm{X}$ chromosomes and autosomes so that even tiny changes in the $\mathrm{X}$ :A signal elicit different sexual fates.

\section{Results}

\section{A Mos1 transposon screen identified an ASE}

To identify ASEs, we conducted a genetic screen for mutations that suppressed the hermaphrodite-specific lethality caused by disrupting two XSEs: fox-1 and sex-1 (Fig. 1B). Reducing the dose of ASEs in an XSE-deficient XX mutant was expected to restore the X:A balance and thereby reestablish dosage compensation and hermaphrodite viability (Powell et al. 2005). The screen was designed to recover both dominant and recessive mutations. The Mos1 transposon was used as the mutagen to permit facile molecular identification of disrupted genes (Bessereau et al. 2001).

One strong candidate emerged from analysis of 9400 Mos1 mutagenized haploid genomes, and three initial experiments suggested that the Mos1-disrupted gene encodes an ASE. First, the y407 suppressor allele restored the viability of fox-1 sex-1 XX mutants to $36 \%$ (Fig. $2 \mathrm{~B}$ ). Inverse PCR of $y 407$ revealed a MosI insertion site within the ORF K10G6.3, and RNAi against K10G6.3 restored the viability of fox-1 sex-1 XX mutants to $27 \%$, a level equivalent to y407. Second, a deletion allele of K10G6.3 (y410) obtained through a directed PCR screen of our C. elegans deletion library also restored the viability of fox-1 sex-1 XX mutants to an equivalent level (24\%) (Fig. 2B). XX and XO animals carrying either mutant allele of K10G6.3 were viable. Third, an extrachromosomal array bearing the cosmid encoding K10G6.3 reduced the viability of $y 407$; fox-1 sex-1 XX animals to that of fox-1 sex-1 XX animals (Materials and Methods). We named the K10G6.3 gene sea-2 to reflect its likely role in sex determination.

sea-2 encodes a zinc finger protein with glutamine/ asparagine-rich repeats

Multiple sea-2 mRNAs are made by different combinations of two alternative SL1 trans-splice acceptor sites at the $5^{\prime}$ end and an alternative splice acceptor that eliminates the sixth exon (Fig. 1C). The longest sea-2 mRNA spans a 9.9-kb genomic region encoding a PQN (prion-like, Q/N-rich) family member of 1727 amino acids (Fig. 1D). SEA-2 also contains six separated zinc finger domains and a metalloprotease motif.

Molecular analysis of sea-2 mutants revealed that neither sea-2 allele is null. For y407, the Mos1 insertion resides in exon 4 and is predicted to cause premature termination of translation for both trans-spliced messages (Fig. 1C). However, y407 cDNAs showed that Mos1 was removed from sea-2 mRNAs through alternative splicing, thereby restoring the reading frame. For y410, the deletion eliminates exons 2 and 3 in the first SL1 trans-spliced mRNA but fails to disrupt the second SL1 trans-spliced mRNA (Fig. 1C). The y410 deletion is predicted to cause premature termination of translation for only the first mRNA.

To isolate a sea-2-null mutant, we mobilized Mos1 in y407 animals and identified an allele (y426) in which all but 5 nucleotides (nt) of Mos1 had been excised (Fig. 1C). The remaining insertion created a premature translational stop codon and the consequent degradation of both SL1 trans-spliced mRNAs (Supplemental Fig. S1). Consistent with y426 being a null allele, y426 increases the viability of fox-1 sex-1 mutants to $50 \%$, a level greater than that achieved by either y407 or y410 (Fig. 2B).

\section{SEA-2 accumulates in nuclei of young embryos during sex determination}

Immunofluorescence experiments with SEA-2 antibodies showed diffuse nuclear accumulation of SEA-2 in embryos of the 20- to 30-cell stage (Fig. 1E), when sex determination begins, and greatly diminished nuclear levels of SEA-2 in embryos beyond the 200-cell stage, after dosage compensation is established (data not shown). SEA-2 antibody staining was present at low levels in y407 mutants and absent in y426-null mutants (Fig. 1E), confirming the specificity of the SEA-2 antibody and the molecular and genetic characterization of the mutants.

Similar nuclear localization and timing of accumulation were observed for the XSE proteins and the ASE SEA-1 (Nicoll et al. 1997; Carmi et al. 1998; Powell et al. 2005; Gladden and Meyer 2007), further implying an early role for SEA-2 in sex determination. The nuclear localization of the zinc finger SEA-2 protein and the presence of PQN protein-protein interaction motifs suggests that SEA-2 acts as a transcription factor that associates with other proteins to achieve transcriptional regulation (Michelitsch and Weissman 2000; Wolfe et al. 2000).

\section{SEA-2 is a bona fide ASE}

To be classified as a bona fide ASE, a gene must fulfill several genetic criteria. First, reducing the dose of an ASE should suppress the XX lethality caused by reducing the dose of XSEs and enhance the XO lethality caused by increasing the dose of XSEs. Second, increasing the dose of an ASE should enhance the XX lethality caused by reducing the dose of XSEs and suppress the XO lethality caused by increasing the dose of XSEs. In fulfilling both criteria, an ASE should act in a dose-dependent manner in the early zygote, the developmental stage in which the $\mathrm{X}$ :A signal is assessed to determine sexual fate.

sea-2 meets all of the criteria for an ASE. First, sea-2 loss-of-function alleles suppress not only the synergistic XX lethality of the fox-1 sex-1(y263) double mutant, but also the XX lethality of the sex-1(y424)-null mutant (from $20 \%$ viability to $34 \% ; P<0.001)$ and the synergistic $\mathrm{XX}$ lethality of the sex-2(y324) sex-1(y263) double mutant (from $0 \%$ viability to $38 \% ; P<0.001$ ) (Fig. 2B). The suppression is dose-dependent: The heterozygous sea$2(y 407) /+$ mutation restores viability of fox-1 sex-1(y263) mutants to $13 \%$, and the homozygous sea-2(y407) mutation restores viability to $36 \%(P<0.001)$ (Fig. $2 \mathrm{~B})$. 
A

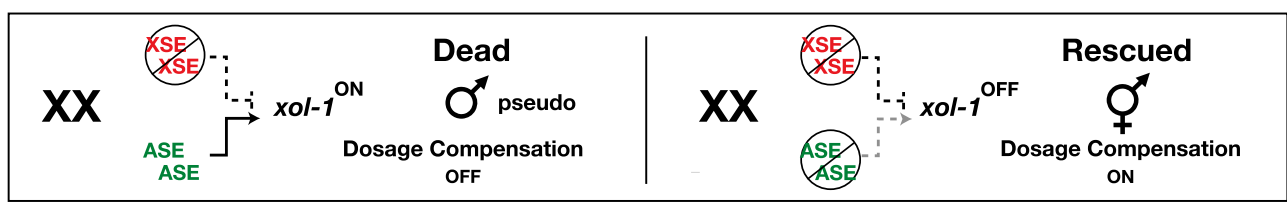

B sea-2 Mutations Suppress the Hermaphrodite Lethality Caused by Reduced XSE Dose

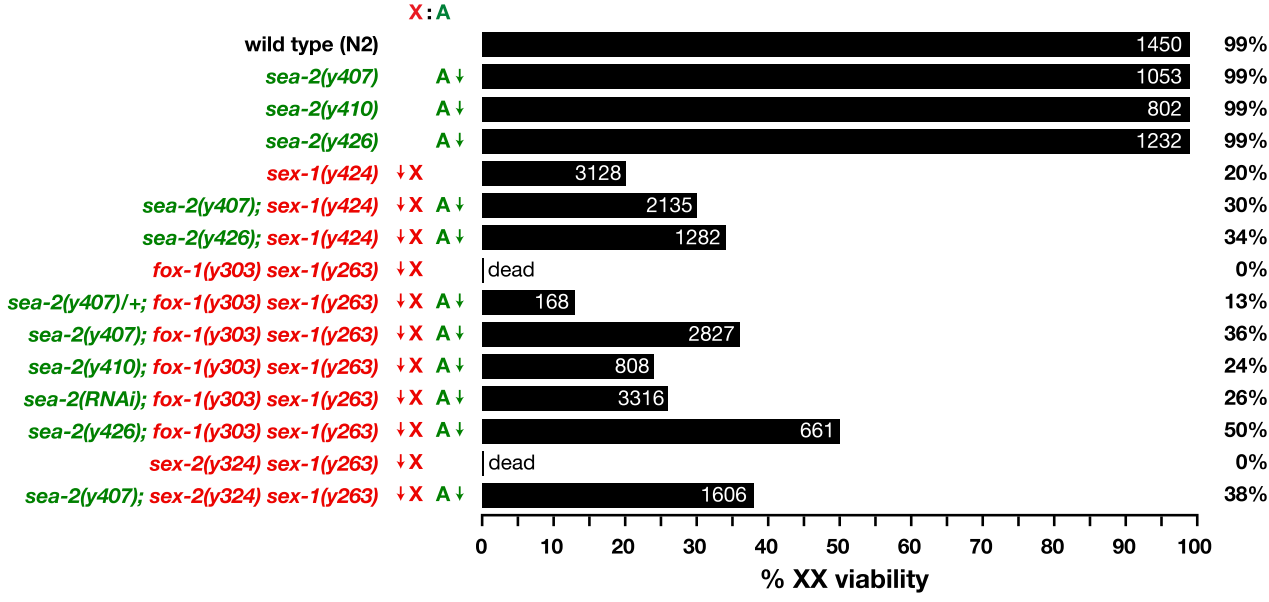

C sea-2 Mutations Enhance the Male Lethality Caused by Increased XSE Dose

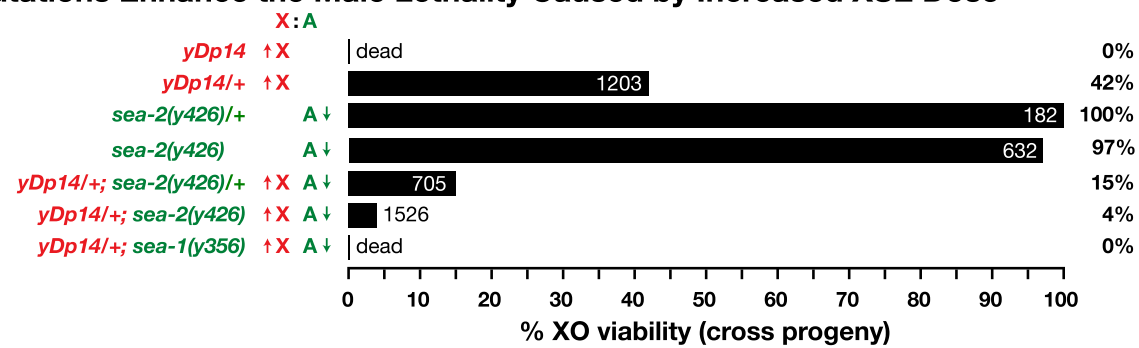

D sea-2 Overexpression Reduces Hermaphrodite Viability

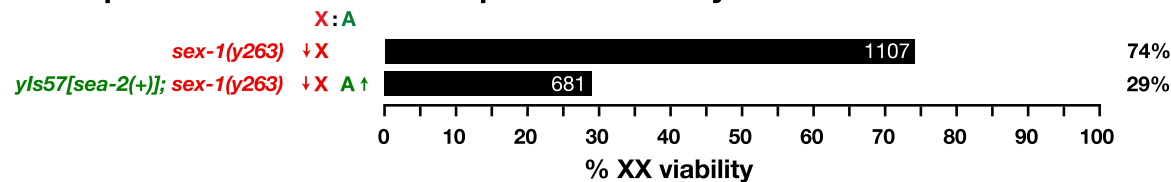

E sea-2 Overexpression Supresses Male Lethality Caused by Increased XSE Dose

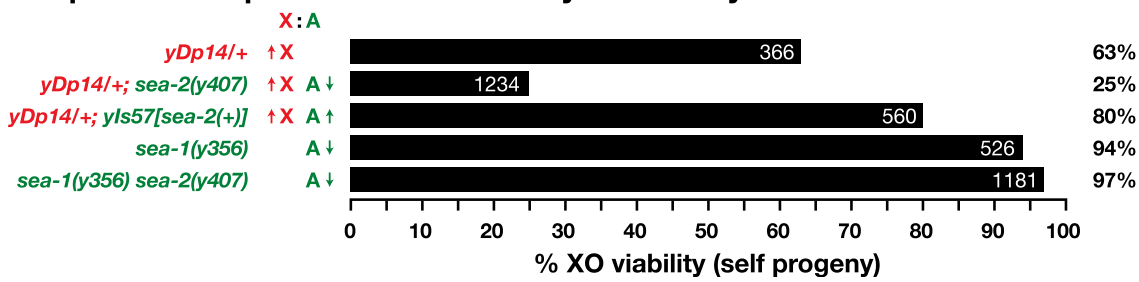

Figure 2. sea-2 fulfills the genetic criteria for an ASE. (A) Genetic properties of XSEs and ASEs in XX animals. Reducing the dose of XSEs causes Xol-1 activation and the consequent masculinization and death of XX animals. Reducing the dose of ASEs in these XSEdeficient XX animals restores the X:A signal, thereby repressing xol-1 and re-establishing viability. $(B-E)$ Histograms show that sea-2 fulfills the genetic properties of an ASE with respect to viability. Genotype of animals assayed for viability is shown on the left, the effect of mutation on $\mathrm{X}$ or A signal is shown by an arrow (up, increase; down, decrease), the percent adult viability is on the $X$-axis, and the total number of embryos counted per experiment is given on each line (white). Formulas for adult viability, crosses (when appropriate), and methods for scoring are described in the Materials and Methods. sea-2 mutations suppress the XX lethality caused by reduced XSE dose $(B)$ and enhance the XO lethality caused by increased XSE dose $(C)$. Elevation of sea-2 dose reduces XX viability $(D)$ and increases viability of XO animals with elevated XSE dose $(E)$. 
Furthermore, sea-2 loss-of-function mutations increase the XO lethality caused by increasing the dose of XSEs, although sea-2 mutations alone appear to have no adverse effect on the viability or morphology of XO animals (Fig. $2 \mathrm{C})$. The viability of $\mathrm{XO}$ animals with one extra copy of fox-1 and ceh-39 carried on the $\mathrm{X}$ duplication $\mathrm{yDp} 14$ was reduced from $42 \%$ to $15 \%$ by sea-2(y 426$) /+$ and to $4 \%$ by homozygous sea-2(y426) $(P<0.001)$. Because the sea-2 mutation was introduced on a paternal chromosome, the enhanced lethality must have been caused by a change in the zygotic dose of sea-2.

Second, increasing the dose of sea-2 suppressed the XO lethality caused by increasing the dose of XSEs and enhanced the XX lethality caused by decreasing the dose of XSEs. Multiple copies of sea-2(+) carried on the integrated array yIs57 increased the viability of $y D p 14 /+$ males from $63 \%$ to $80 \%(P<0.001)$ (Fig. $2 \mathrm{E})$ and decreased the viability of sex-1(y263) XX mutants from $74 \%$ to $29 \%$ $(P<0.001)$ (Fig. 2D). Together, these results show that sea-2 is an ASE that counters the action of XSEs to promote the male fate.

\section{ASEs function cumulatively}

Analysis of sea-1 and sea-2 mutant combinations revealed that the two ASEs act cumulatively to oppose XSEs. The sea-1(y356) sea-2(y407) double combination increased the viability of $\operatorname{sex}-1$ (y424) XX-null mutants from $20 \%$ to $77 \%(P<0.001)$, while the single sea-1(y356) and sea-2(y407) mutations increased the viability to only $51 \%(P<0.001)$ and $30 \%(P<0.001)$, respectively (Fig. 3A). Furthermore, sea-1 and sea-2 mutations act together in a dominant fashion to suppress the XX lethality. While the heterozygous sea-1(y356)/+ mutation failed to increase the viability of fox-1(y303) sex-1(y263) mutants (Fig. 3A) and the heterozygous sea-2(y407)/+ mutation only increased the viability from $0 \%$ to $13 \%(P<0.001)$ (Fig. $2 B)$, the trans-heterozygous sea-1/sea-2 combination increased the viability to $36 \%(P<0.001)$, and the homozygous sea-1 sea-2 combination increased the viability to $70 \%(P<$ 0.001) (Fig. 3A).

In reciprocal experiments, increasing the dose of the wild-type sea-1 and sea-2 genes decreased the viability of $\mathrm{XX}$ animals in a cumulative manner. At $25^{\circ} \mathrm{C}$, multiple copies of either sea-1 (yIs61) or sea-2 (yIs57) had only a small effect on XX viability (89\% and 98\%, respectively), but multiple copies of both reduced the viability of $\mathrm{XX}$ animals to $52 \%(P<0.001)$ (Fig. $3 \mathrm{~B})$. The viability was restored to $93 \%$ by a xol-1 mutation, showing that the XX lethality caused by increased doses of sea-1 and sea-2 was due to misregulation of xol-1 (see Supplemental Fig. S4A for similar experiments conducted at $20^{\circ} \mathrm{C}$ ). Thus, ASEs, like XSEs, function together to communicate the sex signal and act predominantly upstream of xol-1 to coordinately regulate both sex determination and dosage compensation.

SEA-1 and SEA-2 act together to communicate the autosomal signal but do not comprise the entire signal. Null alleles of neither sea-1 nor sea-2 suppressed any of the XX lethality caused by null alleles of both fox-1(y303) and sex-1(y424), even though null alleles of either ASE partially suppressed the synergistic XX lethality caused by the fox-1(y303)-null allele and the sex-1(y263) partial loss-of-function allele (Fig. 3A). Furthermore, only $17 \%$ of sea-1(y356) sea-2(y426); fox-1(y303) sex-1(y424) quadruple XX mutants are viable. Thus, while sea-1 and sea-2 are important ASEs, they do not constitute the entire autosomal signal (Fig. 3A).

Evidence of additional ASEs came from our finding that the candidate ASE mutation y379, which was recovered in an earlier EMS-based genetic screen (Powell et al. 2005) but was not identified molecularly, behaves as a bona fide ASE mutation. We named the gene sea-3. The sea-3(y379) mutant allele partially suppresses the lethality of fox-1(y303) sex-1(y263) mutants and further suppresses the lethality of fox-1(y303) sex-1(y424)-null mutants bearing sea-1and sea-2-null mutations (Fig. 3A). Forty-six percent of the sea-3(y379); fox-1(y303) sex-1(y263) XX triple mutants were viable compared with zero of the fox-1 sex-1 mutants, and $42 \%$ of sea-1(y356) sea-2(y426); sea-3(y379); fox-1(y303) sex-1(y424) XX quintuple mutants were viable compared with $17 \%$ of the sea-1(y356) sea-2(y426); fox1(y303) sex-1(y424) quadruple XX mutants (Fig. 3A). The fertility of the quintuple was also superior to that of the quadruple: Per adult, an average of 120 embryos were produced compared with 44 embryos, respectively.

In reciprocal experiments, all sea-1(y356) sea-2(y426) $\mathrm{XO}$ animals were viable, but $16 \%$ of the sea-1(y356) sea2(y426); sea-3(y379) XO animals were inviable (Fig. 3C), showing that sufficient ASE function had been disrupted to block the full male-promoting activity of xol-1. The cumulative effect of sea-1, sea-2, and sea-3 mutations in countering XSEs shows that ploidy, the autosomal component of the X:A signal, appears to be communicated by a set of discrete ASEs in a manner envisioned by Bridges for flies (Bridges 1921; see the Discussion).

\section{SEA-2 also controls sex determination and dosage compensation independently of xol-1}

Precedent that an X:A signal element can control sex determination and dosage compensation by acting in two different capacities was set previously by sex-1 (Gladden et al. 2007). SEX-1 functions as both an XSE to repress xol-1 and an activator of hermaphrodite-promoting genes that function downstream from xol-1 to activate dosage compensation (Supplemental Fig. S3A,B; Gladden et al. 2007). We asked whether sea-2 also acts in two capacities. Our prior experiments showed that most, but not all, of the XX lethality caused by a sex-1 mutation is suppressed by a xol-1 mutation, and the residual lethality can be enhanced by RNAi against $s d c-2$, a gene that acts downstream from xol-1 to trigger assembly of the DCC onto X (Supplemental Fig. S3A). We show here that a sea-2 mutation can partially suppress the residual XX lethality of Xol-1 sex-1 mutants (Supplemental Fig. S3B) and can partially suppress the enhanced XX lethality caused by $s d c-2(R N A i)$ of xol-1 sex-1 mutants (Supplemental Fig. S3A). Moreover, increased dosage of sea-2 assists $s d c-2$ (RNAi) in suppressing the XO lethality caused by a xol-1 mutation (Supplemental Fig. S3C). Our combined results show that sea-2 functions 

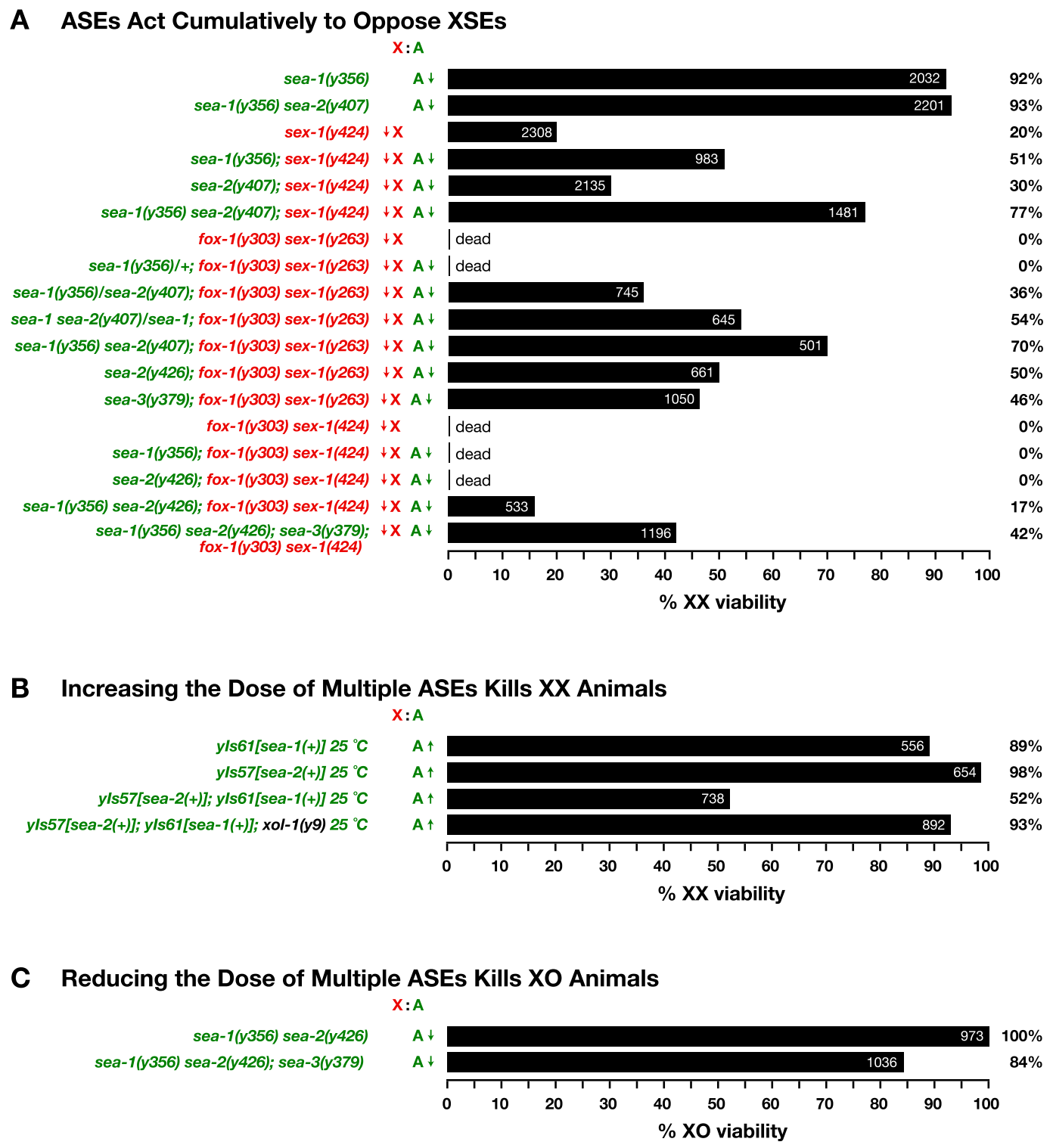

Figure 3. sea-1, sea-2, and sea-3 act cumulatively to communicate ploidy. (A) Mutations in sea-1, sea-2, and sea-3 together increase the viability of XSE-deficient XX animals more completely than knockout of only one or two ASEs. (B) Increased dosage of sea-1 and sea-2 more effectively reduces the viability of XX animals than increased dose of either alone. (C) Mutation of sea-1, sea-2, and sea-3 together reduces XO viability. All strains carried the him-8(e1489) mutation, which increases the proportion of XO progeny to $\sim 37 \%$. Viability of XO animals bearing ASE mutations was determined by assessing the number of adult male progeny relative to those in the him-8 control.

in two capacities to control the male modes of sex determination and dosage compensation: as an ASE to activate xol-1 and as a repressor of a hermaphrodite-promoting activity that acts downstream from xol-1.

\section{SEA-2 is an activator of xol-1 transcription}

XSEs communicate X-chromosome number by reducing the level of functional xol-1 transcripts in a dose-dependent manner through two means: transcriptional repression and alternative mRNA splicing control. Because ASEs oppose XSEs, we asked whether SEA-2 communicates the ploidy by increasing the level of functional xol-1 transcripts. To assess the effect of SEA-2 on xol-1 transcription, we used the integrated yIs33 multicopy reporter transgene Pxol-1::lacZ, in which the xol-1 promoter controls transcription of lacZ (Nicoll et al. 1997), to compare $\beta$-galactosidase activity among wild-type XX and $\mathrm{XO}$ embryos and XX embryos with increased sea$2(+)$ dose.

We first showed that the xol-1 transcriptional reporter faithfully reproduces the activity states of xol-1 in wildtype XX and XO embryos (Fig. 4A,B). Of embryos produced from yIs33 XX animals, 90.1\% had no detectable 
A

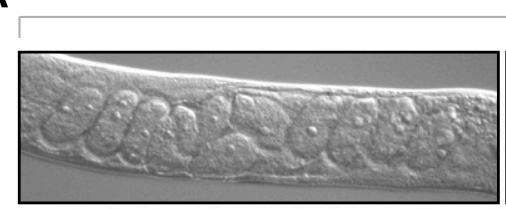

wild type (XX)
Pxol-1::lacZ

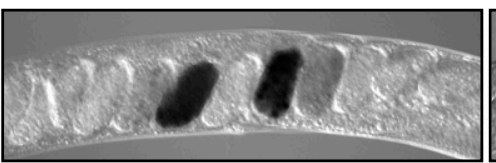

him-8 (XX + XO)

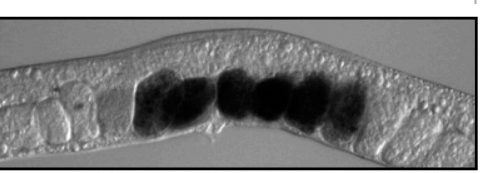

yls57[sea-2(+)] (XX)

B

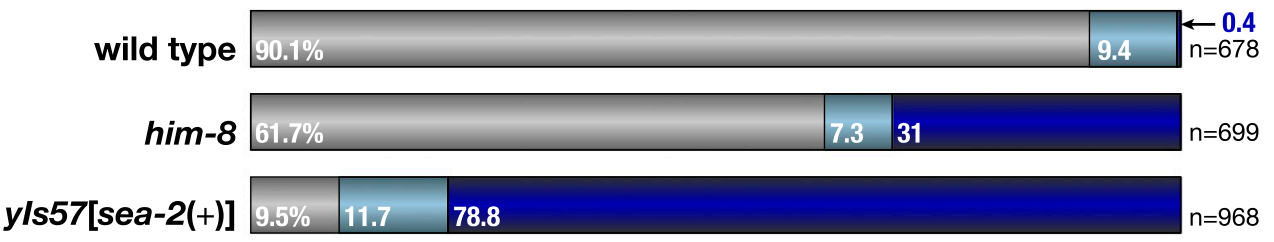

C
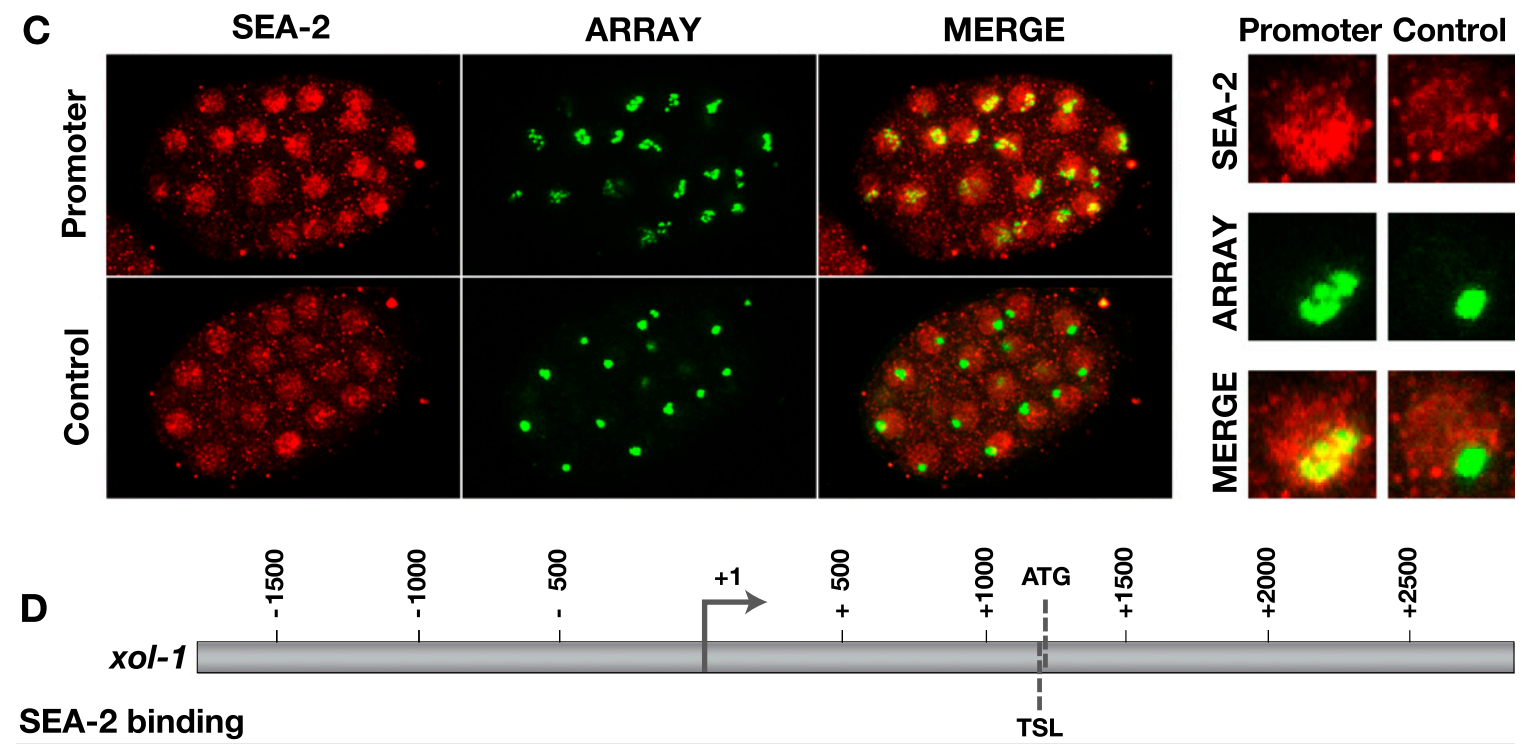

SEA-2 binding

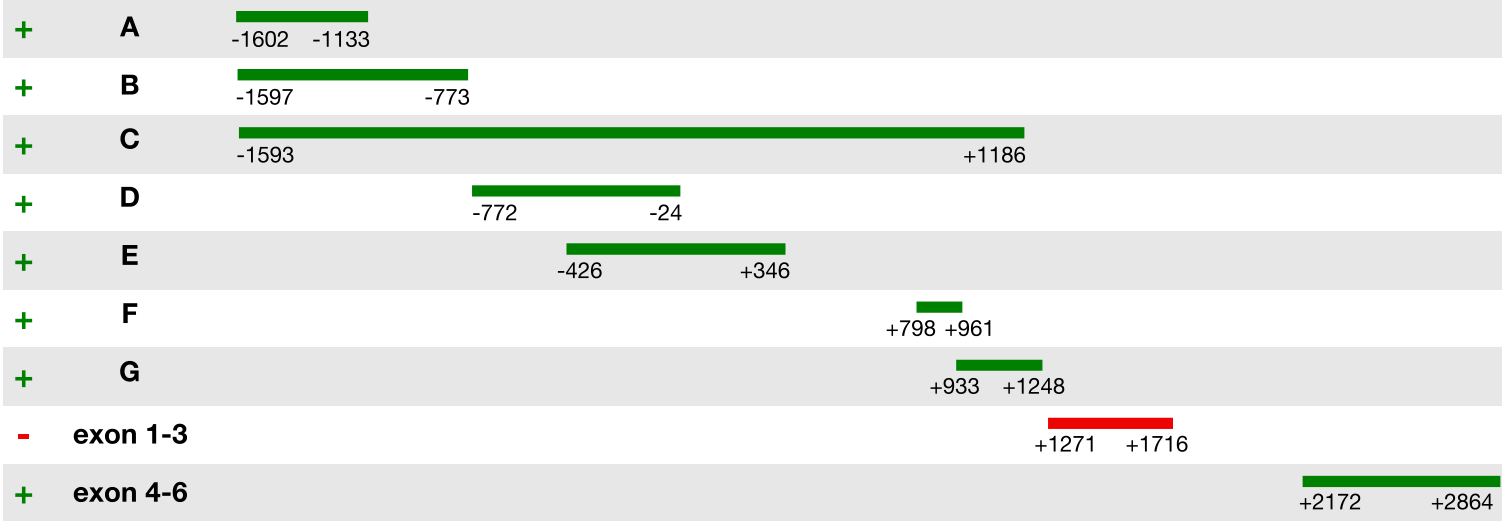

Figure 4. SEA-2 activates xol-1 transcription by binding to the xol-1 promoter. $(A, B)$ Increased dose of sea-2 activates transcription of xol-1 in XX embryos. (A) Nomarski images of hermaphrodite gonads at $25^{\circ} \mathrm{C}$ from wild-type, him- 8 , and yIs57[sea-2(+)] transgenic animals carrying the integrated Pxol-1::lacZ transcriptional reporter. Hermaphrodites were grown at $25^{\circ} \mathrm{C}$ and stained for $\beta$-galactosidase activity. Embryos within the gonads have undetectable (light gray), low (gray), or high (black) levels of $\beta$-galactosidase activity. While wild-type and yIs57[sea-2(+)] hermaphrodites both produce only $0.2 \%$ XO embryos, yIs57 hermaphrodites produce a higher frequency of embryos with high $\beta$-galactosidase activity, revealing that elevated sea- 2 dose activates xol-1 in XX embryos. The level of $\beta$-galactosidase activity in yIs57 XX embryos resembles that in XO embryos. The proportion of embryos with high and low $\beta$-galactosidase activity in him-8 gonads reflects the expected proportion of XX to XO embryos. (B) Quantification of embryos having undetectable (gray), low (light blue), or high (dark blue) $\beta$-galactosidase activity within gonads of hermaphrodites with listed genotypes. $n$ is the total number of embryos scored; percentages of embryos with each class of activity are indicated. (C) SEA-2 binds to xol-1 in vivo. Confocal images of wild-type embryos bearing xol-1 promoter arrays (fragment C in $D$ ) or control arrays both stained with SEA-2 (red) and GFP (green) antibodies. Arrays also contain a transgene encoding a GFP-tagged lac repressor protein (lacI::GFP) and multiple copies of lac operator sequences (lacO). lacI::GFP proteins bind to lacO sequences, allowing GFP antibodies to mark xol-1 arrays. If endogenous SEA-2 protein binds to the xol-1 promoter, SEA-2 antibodies colocalize (yellow) with GFP antibodies on arrays with xol-1 but not control sequences. (D) Assessment of SEA-2-binding ability and map of assayed xol-1 fragments in the promoter (1602 bp upstream of the TSS) and gene body (first $2864 \mathrm{bp}) .(+)$ SEA-2 binding to arrays, $(-)$ no or rare binding to arrays. 
$\beta$-galactosidase activity, and $0.4 \%$ had high activity. These results are consistent with the low level of xol-1 activity in wild-type $\mathrm{XX}$ embryos, the low proportion $(0.1 \%)$ of XO embryos in a wild-type brood, and the high level of xol-1 activity in these rare XO embryos. Of embryos produced from yIs33 XX animals bearing a him-8 mutation, which elevates the proportion of $\mathrm{XO}$ progeny to $37 \%, 31 \%$ had high $\beta$-galactosidase activity, consistent with the increase in XO progeny. While the reporter transgene faithfully recapitulates xol-1's sexspecific regulation, it does not reflect the absolute level of endogenous xol-1 transcripts because the reporter is present in multiple copies, and its lacZ transcript level is higher than the endogenous xol-1 transcript level. We next showed that increasing the dose of the wild-type sea-2 gene increases xol-1 transcription in XX animals (Fig. 4A). An array (yIs57) carrying multiple copies of sea-2(+) increased the proportion of Pxol-1::lacZ-bearing $\mathrm{XX}$ embryos having high $\beta$-galactosidase activity from $0.4 \%$ to $78.8 \%$. These results indicate that SEA-2 activates xol-1 transcription either directly or indirectly, and ASEs transmit ploidy by activating xol-1 in a dosedependent manner.

\section{Identification of the xol-1 transcription start site (TSS)}

ASEs and XSEs antagonize each other to communicate the X:A signal by regulating Xol-1 transcription in opposite directions. To assess the mechanism by which these signal elements regulate xol-1, we first had to determine xol-1's TSS. xol-1, like most genes in C. elegans, undergoes a cotranscriptional processing event in which the 5 ' end of the nascent transcript is replaced by a common 22-nt leader RNA through a trans-splicing mechanism. For xol-1, the trans-spliced leader (TSL) is spliced $14 \mathrm{nt}$ upstream of the AUG start of translation (Rhind et al. 1995).

PCR amplification of xol-1 cDNA made from embryo RNA revealed the TSS to be far upstream of the TSL site (Supplemental Fig. S5B). A robust PCR product placed the TSS at least 546 base pairs (bp) upstream of the TSL, and a faint product placed it further upstream, to at least 1037 bp. Because trans-splicing is cotranscriptional and TSSs are rarely identified accurately from accumulated RNA, we confirmed and extended our understanding of the xol-1 TSS through our ongoing efforts to map genomewide TSSs from nascent transcripts. Global run-on sequencing (GRO-seq) reactions were used to isolate nascent transcripts, and transcripts with $5^{\prime}$ CAPs were then enriched and sequenced (WS Kruesi, LJ Core, CT Waters, JT Lis, and BJ Meyer, in prep.). The analysis confirmed our cDNA analysis and placed the xol-1 TSS at $1203 \mathrm{nt}$ upstream of the TSL, just downstream from a well-placed nucleosome (Supplemental Fig. S5A). In the early XX embryo, when xol-1 is active prior to its repression by XSEs, this -1 nucleosome carries the H3K4me3 and $\mathrm{H} 3 \mathrm{~K} 27 \mathrm{ac}$ post-translational modifications typical of active transcription (Supplemental Fig. S5C). Later in development, when xol-1 is inactive, the modifications are absent.
The XSES SEX-1 and CEH-39 repress xol-1 transcription directly by binding to discrete sites in the promoter and gene body

To understand the basis for the molecular tug of war between XSEs and ASEs, we asked whether XSEs and ASEs bind directly to xol-1 regulatory regions to control its transcription. Previous immunocytochemical experiments showed that SEX-1 colocalized in vivo with a xol-1 promoter fragment that extends 1598 bp upstream of the TSS, drives sex-specific expression of a Pxol-1::1acZ transgene, and is responsive to sex-1 mutations (Carmi et al. 1998). To detect SEX-1-binding sites within xol-1, we expressed and partially purified SEX-1 from Sf-9 insect cells and used SEX-1 in electrophoretic mobility shift assays (EMSAs) to survey 300-bp overlapping DNA probes spanning $1785 \mathrm{bp}$ upstream of the TSS, the 1203-bp outron, and the first three exons of xol-1 (Fig. 5A; Supplemental Fig. S6A). Two sets of overlapping probes (J, K, and L, and $\mathrm{P}$ and Q) exhibited binding. The overlapping regions were further dissected by assaying SEX-1 binding to 50-bp overlapping probes. Five independent 25-bp SEX-1-binding regions were found: four in the promoter region overlapping the -1 nucleosome and one further along in the gene between the start points of transcription and translation. (Fig. 5A-C; Supplemental Figs. S5A, S6A,B).

The specificity in SEX-1 binding was established by antibody supershift experiments and mutational analysis. Increasing concentrations of SEX-1 antibody efficiently supershifted the already-shifted probes harboring the five candidate binding sites, demonstrating that SEX-1 was indeed bound to the probes (Fig. 5C; Supplemental Fig. S6B). Each of the five 25-bp binding regions encodes a close variant of the consensus nuclear hormone receptor (NHR)binding site AGGTCA (Fig. 5C; Mangelsdorf et al. 1995). To validate these sequences as bona fide SEX-1-binding sites, we changed the first three bases of each candidate binding site to TTT and examined binding to the mutated sites (Fig. 5B). SEX-1 bound to none of the mutant probes. Our two findings that (1) SEX-1 binding was disrupted by mutation of the putative NHR response element and (2) the shift in wild-type probes was dependent on SEX-1 indicate that SEX-1 binds directly to xol-1 regulatory sequences in vitro at five different sites. Of note, the closest two SEX-1 response elements are 48 bp apart, and no other NHR response elements reside nearby, suggesting that SEX-1 does not bind as a homodimer.

To identify CEH-39-binding sites, we performed EMSAs using CEH-39 produced from in vitro transcriptiontranslation reactions and the 300-bp overlapping probes spanning the xol-1 promoter and first three exons (Fig. 5D). CEH-39 bound to three sets of overlapping probes (H and $\mathrm{I}, \mathrm{K}$ and $\mathrm{L}$, and $\mathrm{M}$ and $\mathrm{N}$ ) and two end probes (A and V) representing the promoter and third exon. Dissection of promoter region A revealed CEH-39 binding to two overlapping 50-bp probes that shared a version of the core ONECUT homeodomain consensus binding site ATTGAT (Fig. 5D,F; Supplemental Fig. S7) (Iyaguchi et al. 2007). CEH-39 binding was abrogated in subsequent EMSAs to site 1 by a mutation that changed the variant of the 


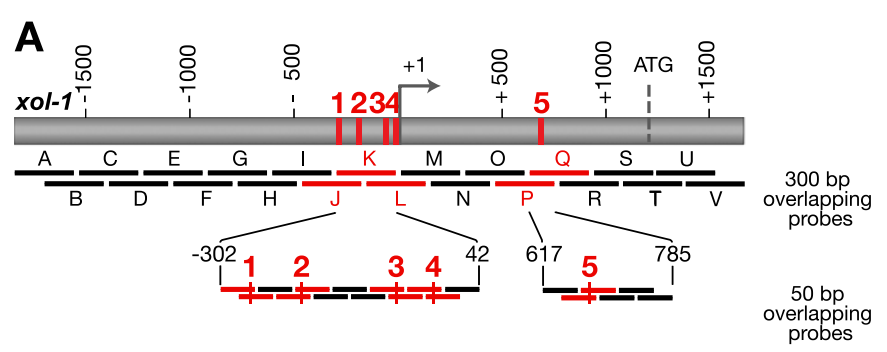

B

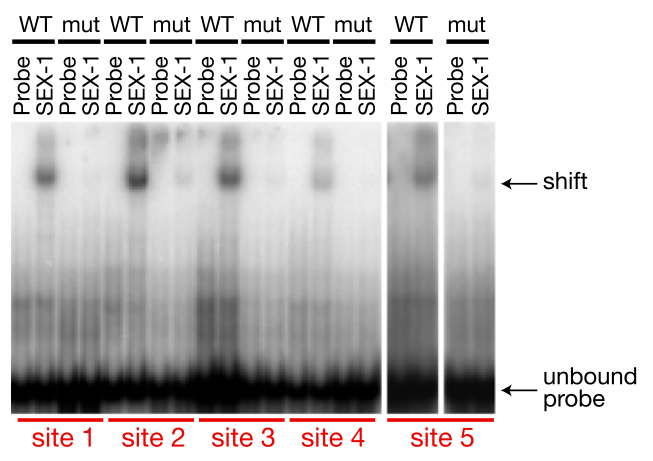

$\square$ SEX-1:

Site 1: ACGTCA

Site 2: AGGGCA

Site 3: AGGTCA

Site 4: AGGTCG

Site 5: AGTTCA

AGGTCA

Canonical NHR

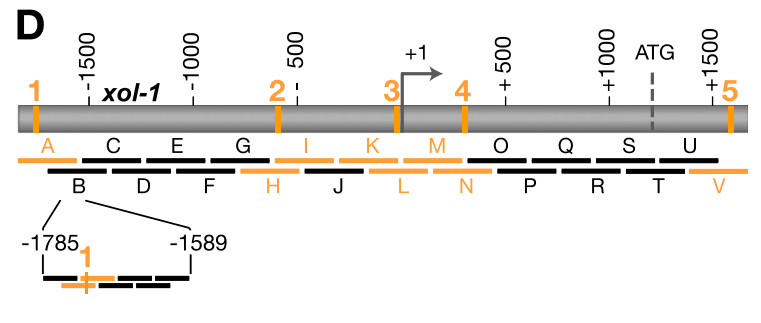

E
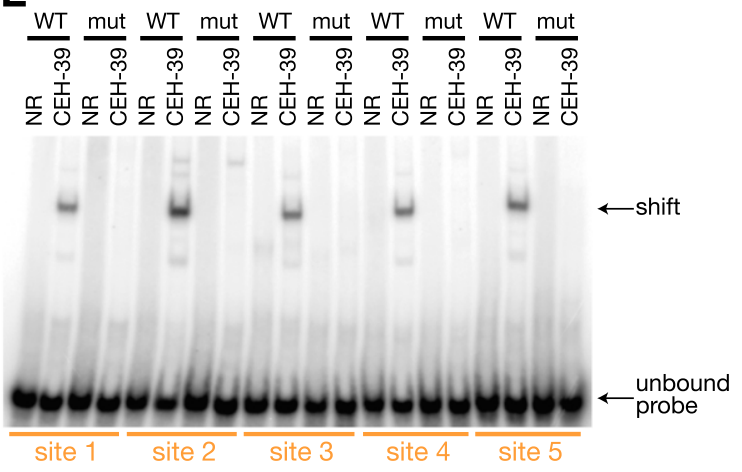

$\mathbf{F}_{\mathrm{o}}$

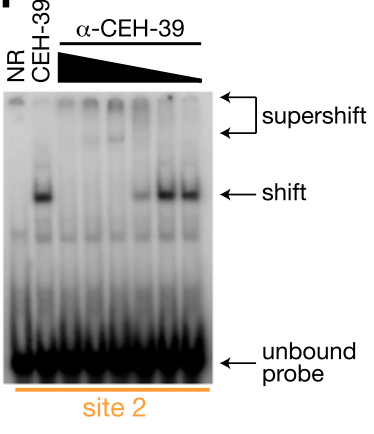

$\square$ CEH-39: Location

Site 1: TTCGAT - 1721

Site 2: ATCGAT ～- 581

Site 3: ATTGAT $\quad-\quad 16$

Site 4: ATTGAT $\quad+298$

Site 5: ATCGAT + +1614

ATTGAT

Canonical OC

G

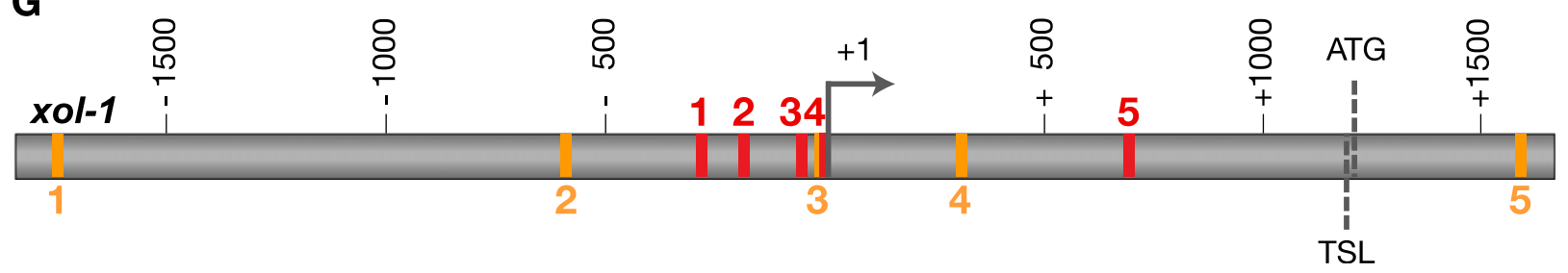

Figure 5. SEX-1 and CEH-39 bind directly to multiple discrete sites in xol-1. (A) Schematic diagram of the xol-1 promoter and the 300bp overlapping ${ }^{32}$ P-labeled DNA fragments used for the SEX-1 EMSAs (A-V) shows the five SEX-1-binding regions (red). Positive probes were subdivided into 50-bp overlapping DNA fragments used to define the five discrete SEX-1-binding sites (red) using EMSAs. (B) Mutation of the nuclear hormone response elements eliminates SEX-1 binding to the 50-bp probes. Shown are SEX-1 EMSAs to either wild-type (WT) (right) or mutant (mut) (left) probes in which the first 3 bases of each SEX-1 response element was mutated to TTT. (C) Antibody supershift experiment for SEX-1-binding site 3. Increasing concentrations of SEX-1 antibody were titrated against a 50-bp probe incubated with a constant amount of SEX-1 extract. Supershifted bands (arrows) demonstrated the presence of SEX-1 in the original shifted protein-DNA complex. Sequences of the five SEX-1-binding sites are compared with a canonical NHR-binding site. Locations of sites are given relative to the TSS. $(D)$ xol-1 schematic for the 300-bp DNA fragments used in EMSAs with CEH-39 shows the location of CEH-39-binding regions (orange). Below is a schematic of 50-bp overlapping DNA fragments used to define the first CEH-39-binding site. (E) The homeodomain element in each CEH-39-binding site is required for CEH-39-dependent mobility shifts. Shown are EMSAs of either wild-type (WT) (right) or mutant (mut) (left) probes in which the homeodomain element within each binding site was mutated to GGGGGG. $(F)$ Antibody supershift experiment for CEH-39-binding site 2. Increasing concentrations of CEH-39 antibody were titrated against the 50-bp probe that was incubated with a constant amount of CEH-39 protein. Supershifted bands (arrows) revealed the presence of CEH-39 in the original shifted band. Sequences and locations of CEH-39-binding sites are compared with a canonical ONECUT homeodomain-binding site. (G) Schematic of xol-1 showing the SEX-1-binding site (red) and CEH39-binding site (orange) relative to the TSS and the acceptor site for the SL1 TSL RNA. 
consensus sequence to GGGGGG (Fig. 5E), thus demonstrating specificity in CEH-39 binding to classical ONECUT sites.

Similar ONECUT consensus sequences were found in each of the other CEH-39-bound probes (Fig. 5F). EMSAs demonstrated CEH-39 binding to unique 50-bp probes centered on each of the wild-type consensus sequences but not to probes carrying the GGGGGG mutated sequence (Fig. 5E). In total, we found three CEH-39-binding sites in the xol-1 promoter: one between the start points of transcription and translation, and one in the third exon. One of the three promoter sites overlaps the -1 nucleosome (Supplemental Fig. S5A). Specificity of CEH-39 binding was further confirmed with antibody supershift experiments for all sites (Fig. 5F; data not shown).

Discovery of a CEH-39-binding site in the third exon helps explain our prior observation that the yIs33 transcriptional Pxol-1::1acZ transgene reporter was responsive to sex-1 mutations but not responsive to ceh-39 mutations (Gladden and Meyer 2007). CEH-39 responsiveness required the reporter to contain the promoter and first three exons of xol-1.

One CEH-39-binding site (site 3) lies immediately adjacent to a SEX-1-binding site (site 4) with no nucleotides in between. Given the proximity of the sites, we tested whether CEH-39 and SEX-1 could bind as heterodimers and repress xol-1 in a synergistic manner. No evidence was found for synergy between SEX-1 and CEH39 binding to the same probe (data not shown). In aggregate, our experiments demonstrate that two XSEs-SEX-1 and CEH-39-bind directly to multiple sites throughout the xol-1 regulatory region to control xol-1.

The ASEs activate xol-1 transcription directly by binding to discrete sites on the promoter and gene body

Although SEA-2 does not contain a well-defined DNAbinding domain, it does contain six separated zinc finger motifs, suggesting that SEA-2 might bind DNA. To assess SEA-2 binding to xol-1, we used the EMSA strategy outlined above using SEA-2 expressed from Sf-9 cells. We were unable to detect binding to any of the 300-bp probes. As an alternative approach, we assayed SEA-2 binding to xol-1 in vivo using an immunocytochemical assay previously used to show colocalization of SEX-1 with the xol-1 promoter (Fig. 4C,D; Carmi et al. 1998). We created transgenic strains carrying extrachromosomal arrays with multiple copies of either the xol-1 promoter, xol-1 promoter truncations, xol-1 coding regions, or a control plasmid. These arrays also contained multiple copies of the lac operator (lacO) and a plasmid expressing a bifunctional lac repressor-GFP fusion protein (lacI:: GFP). Colocalization of SEA-2 antibodies with lacI-GFP bound to lacO sites on the arrays implies SEA-2 binding to xol-1. SEA-2 colocalized with the full xol-1 promoter, all of the promoter truncations, and exons 4-6 but failed to localize with the control and with exons 1-3 (Fig. 4C,D). These data show that SEA-2 associates with xol-1 directly or indirectly via multiple sites throughout the gene.
In contrast to SEA-2, the ASE SEA-1 performed well in EMSA studies and enabled us to demonstrate that SEA-1 binds directly to the xol-1 promoter (Fig. 6A-E; Supplemental Fig. S8). A SEA-1 fusion protein carrying an $\mathrm{N}$-terminal GST tag was purified from bacteria and used in EMSA reactions with the 300-bp overlapping xol-1 probes used for the XSE analysis. SEA-1 bound to two sets of overlapping probes (F and $G$, and $R$ and $S$ ) and one individual probe $(\mathrm{K})$. The regions of overlap and the unique $\mathrm{K}$ probe were dissected into small overlapping probes and analyzed with EMSAs (Fig. 6A; Supplemental Fig. S8). Four distinct SEA-1-binding sites were found throughout the xol-1 promoter and one was found between the start points of transcription and translation. Two promoter sites overlap the -1 nucleosome (Supplemental Fig. S5A). The specificity of binding was confirmed by antibody supershift experiments (Fig. 6B; data not shown). The probes that bound SEA-1 do not harbor sequences resembling known T-box DNA-binding sites, except probes to binding site 1, which have limited similarity to the Brachyury half-site TTTCACACCT (Fig. 6E; Kispert and Herrmann 1993; Casey et al. 1998).

To identify the SEA-1-binding sites with greater precision, we performed DNase 1 footprinting assays with purified GST-SEA-1 on probes spanning the overlapping binding regions (Fig. 6D; Supplemental Fig. S9). Clear, distinct SEA-1 protected sites were found within each of the regions of overlap, all with unique sequences. Site 2 had the largest footprint. It had two shifted bands in EMSAs (Supplemental Fig. 8), suggesting that site 2 might have more than one SEA-1-binding site or that SEA-1 binds as a homodimer to this site and as a monomer to other sites. The importance of the identified sequences in SEA-1 binding was established through EMSAs with probes containing randomized sequences (Fig. 6C). SEA-1 binding was negligible to probes with randomized sequences but robust to the consensus T-box site used as a positive control.

SEA-1-binding sites are interspersed with SEX-1 and CEH-39 sites, but no clear overlap is evident between the ASE and XSE sites, implying that the antagonism between ASEs and XSEs is not simply due to direct competition for binding to overlapping sites (Fig. 6E). This interpretation is supported by the finding that the SEX-1 protein can supershift a SEA-1-bound DNA fragment carrying XSEand ASE-binding sites, indicating that both elements can bind simultaneously to a single fragment of DNA (Supplemental Fig. 10).

Activation and repression of xol-1 transcription in vivo occurs via the XSE- and ASE-binding sites

To assess the importance of the XSE- and ASE-binding sites in vivo for the regulation of xol-1, we generated strains with integrated, single-copy xol-1 transgenes bearing mutations in XSE- or ASE-binding sites and assayed their effect on hermaphrodite viability in wild-type and XSE- or ASE-deficient strains (Fig. 7A-C). The endogenous xol-1 gene was knocked out in these strains, making the transgenes the sole source of xol-1. Three lines of evidence 
A

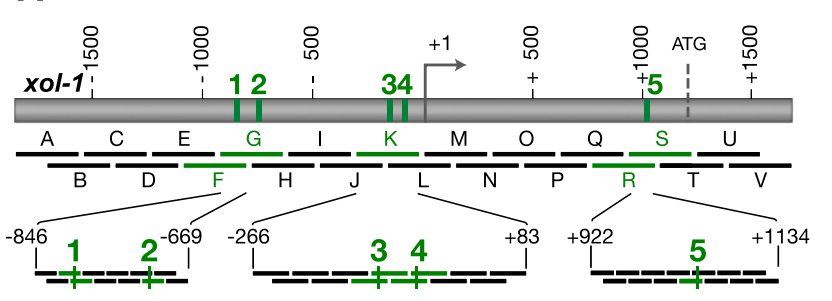

B

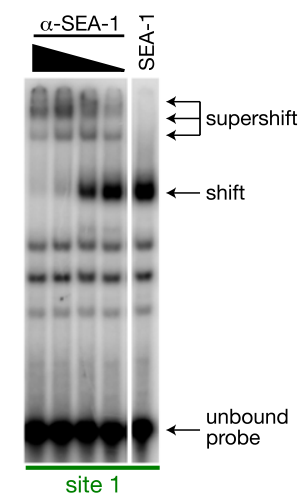

C
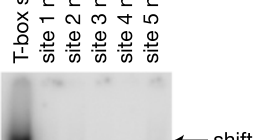

SEA-1:

Site 1: TCACATT

Site 2: TCCTCGCATGTGTTCATTTATACT

Site 3:

Site 5:

GCTCTATCGC

GCTCTA

TTTCACACCT

Canonical T-Box

D

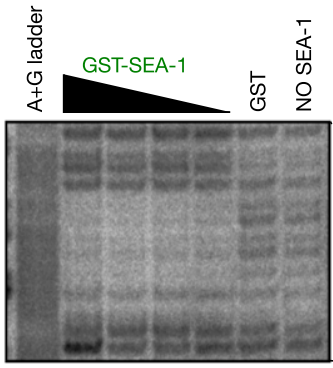

SEA-1 binding site 3

EMSA
overlap

footprint

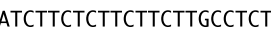

CATCTTCTCTTCTTCT

GTAGAAGAGAAGAAGA

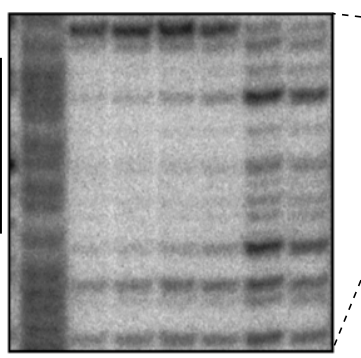

SEA-1 binding site 4

ATGACAACTGCGCTCTATCGCCAC

GCTCTATCGCCACG CGAGATAGCGGTGC

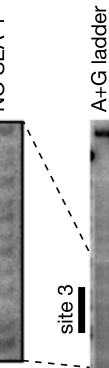

일
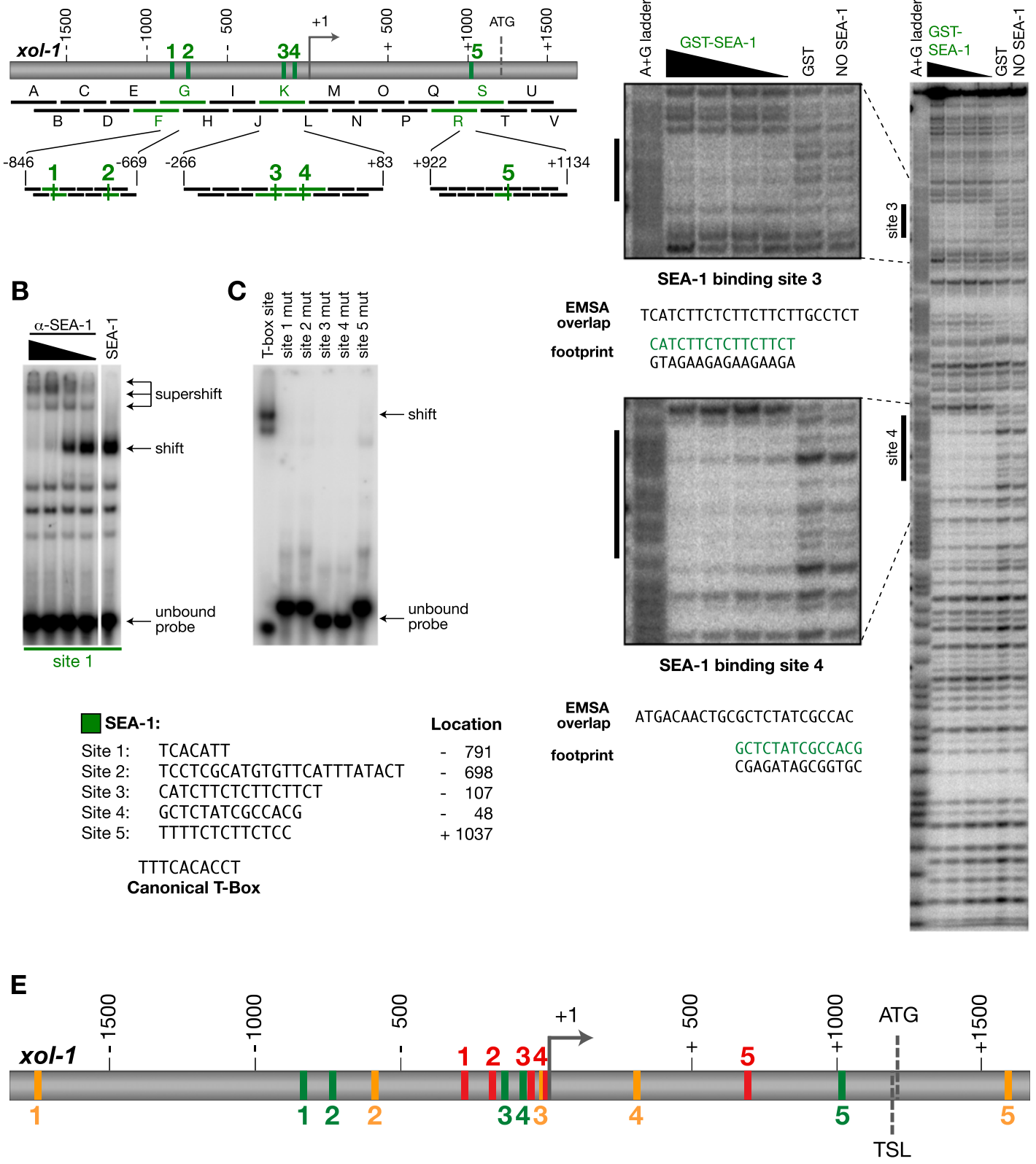

Figure 6. SEA-1 binds directly to multiple discrete sites in xol-1. (A) Schematic diagram of 300-bp xol-1 DNA fragments used for EMSAs with SEA-1 shows the location of five SEA-1-binding regions (green). Below are the 30- or 50-bp overlapping fragments analyzed to define the five SEA-1-binding sites (green). (B) Antibody supershift experiment for SEA-1-binding site 1. Increasing concentrations of SEA-1 antibody were titrated against a 50-bp probe incubated with a constant amount of SEA-1 protein. Supershifted bands (arrows) revealed the presence of SEA-1 in the original shifted protein-DNA complex. $(C)$ DNA sequences identified by the overlapping probes are required for the SEA-1-dependent mobility shifts. Shown are EMSAs with a probe of the consensus T-box site and probes carrying randomized versions of the five SEA-1-binding sites (mut). (D) DNase I footprinting assays identified five noncanonical T-box-binding sites for SEA-1. Shown is the 150-bp DNA fragment containing SEA-1-binding sites 3 and 4. The probe was incubated with either no protein, $600 \mathrm{ng}$ of GST control, or a dilution series of 600, 300, 150, and $75 \mathrm{ng}$ of GST-SEA-1. The protected regions (black bars) are enlarged at the left of the full-length gel. Each footprinting gel had a labeled A+G ladder as a marker for the protected sequences. Below each enlarged footprint are the sequences protected by SEA-1 compared with the overlapping sequence in the probes bound by SEA-1 in EMSAs. The radiolabeled and interrogated DNA strand is shown in black, and the reverse strand in green matches the site shown in $E$. The five SEA-1-binding sites identified by footprinting assays are compared with a canonical T-box-binding site. $(E)$ Schematic of xol-1 with the SEA-1-binding site (green), SEX-1-binding site (red), and CEH-39-binding site (orange).

showed that mutating the XSE- and ASE-binding sites in Xol-1 recapitulated the phenotypes caused by disrupting the XSE and ASE genes. First, disrupting all SEX-1- and
CEH-39-binding sites in a xol-1 transgene killed nearly all Xol-1 transgenic XX mutant animals, just as disrupting both ceh-39 and sex-1 killed all XX animals (Fig. 7A). The 
A Mutation of ASEs suppresses the $\sigma^{\prime}$ lethality due to deletion of XSE binding sites in a xol-1 transgene

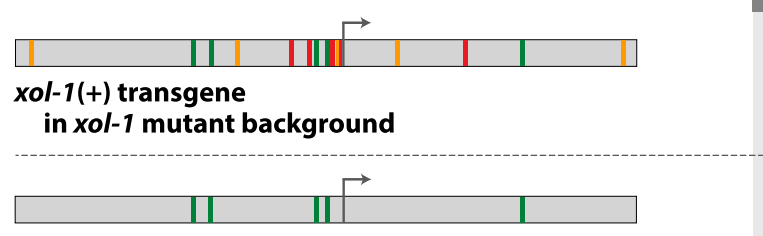

xol-1 transgene with $\triangle \mathrm{SEX}-1$ and $\triangle \mathrm{CEH}-39$ sites in xol-1 mutant background

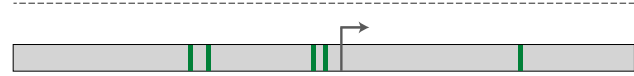

xol-1 transgene with $\triangle$ SEX-1 and $\triangle \mathrm{CEH}-39$ sites

in sea-1 sea-2; xol-1 mutant background

B Deletion of SEA-1 binding sites in a xol-1 transgene suppresses the $\sigma^{\prime \prime}$ lethality of sex-1 null mutants

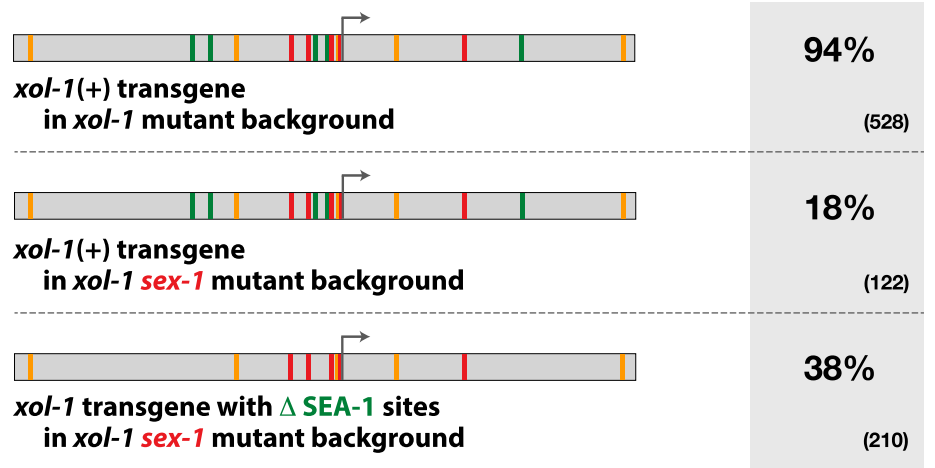

Figure 7. Mutation of XSE- and ASE-binding sites in xol-1 transgenes, the sole source of xol-1 in the strains, recapitulates the phenotypes caused by disrupting the XSE and ASE genes. Single-copy, integrated xol-1 transgenes bearing mutations in either XSE- or ASE-binding sites were assayed for their effect on hermaphrodite viability in different mutant backgrounds. Descriptions of xol-1 transgenes and genotypes of assayed XX animals are indicated below each schematic of the regulatory region. Viability is shown to the right, with the number of embryos counted $(n)$ in parentheses. Hermaphrodite viability was calculated from at least three independent experiments using the formula [(no. of adult hermaphrodites)/(total no. of embryos)] $\times 100$. (A) Disruption of the ASE genes sea-1 and sea-2 in XX animals carrying a xol-1 transgene lacking binding sites for the XSEs SEX-1 and CEH-39 restored XX viability to nearly wild-type levels. In the control strain bearing mutations in sea-1 and sea-2, $98 \%$ of animals were viable $(n=723)$. The genotype was sea-1(y356) sea2(y407); xol-1(y9); yIs[xol-1]. (B) Disruption of SEA-1binding sites in a xol-1 transgene partially suppressed the XX lethality of sex-1(null) XX mutants. $(C)$ Disruption of SEA-1-binding sites in a xol-1 transgene partially suppressed the XX lethality of fox-1 sex-1 XX mutants. In the control strain carrying a xol-1 transgene with disrupted SEA-1-binding sites, 93\% of animals were viable $(n=653)$.

\section{The xol-1 transgene lacking SEA-1 binding sites} suppresses the $\sigma^{\prime \prime}$ lethality due to XSE mutations

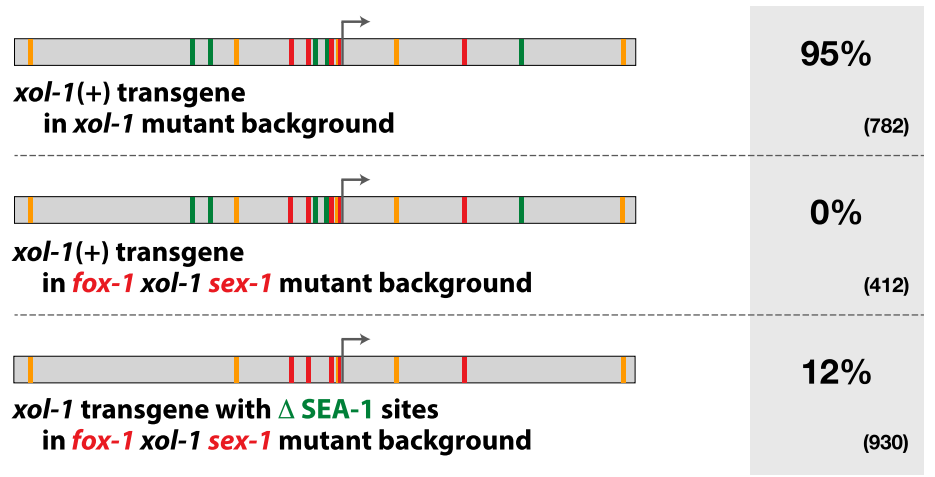

hermaphrodite lethality caused by disrupting XSE-binding sites in the transgene was fully suppressed by disrupting both the sea-1 and sea-2 genes (Fig. 7A).

Analysis of xol-1 transcript levels from wild-type and XSE-binding-defective transgenes further corroborated the function of the XSE-binding sites in vivo (Supplemental Table S1). xol-1 transcript levels from a wild-type transgene were elevated 3.5-fold in a sex-1(y424)-null mutant compared with a sex-1 $1+\mid$ mutant, in close agreement with the 2.8-fold increase in xol-1 transcript level from the endogenous gene in a sex-1(y424) mutant. Furthermore, xol-1 transcript levels from a xol-1 transgene with mutations in all SEX-1- and CEH-39-binding sites were increased further, to 6.9-fold, consistent with the mutations eliminating the repressive function of XSEs.

Second, just as a sea-1 mutation prevented the death of many sex-1 XX mutants (Fig. 3A), knocking out the SEA-1binding sites in the xol-1 transgene prevented the death of many sex-1 XX mutants that would be caused by a wild-type xol-1 transgene (Fig. 7B). Third, just as a sea-1 mutation prevented the death of many fox-1 sex-1 double mutants (Powell et al. 2005), knocking out the SEA-1binding sites in the xol-1 transgene prevented the death of many fox-1 sex-1 XX mutants that would be caused by 


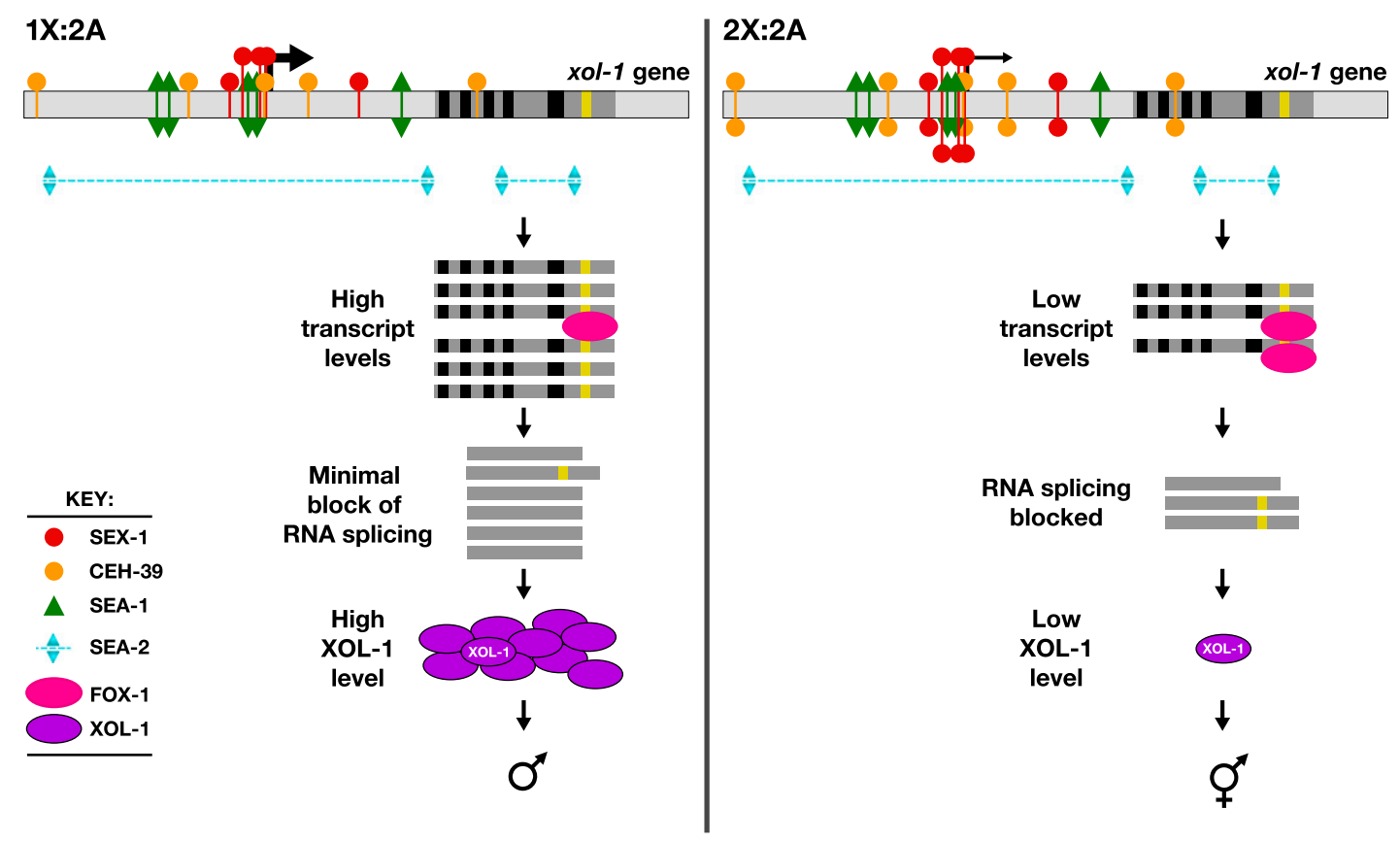

Figure 8. Primary sex determination: model for X:A signal assessment. XSEs and ASEs bind directly to numerous sites on xol-1 and antagonize each other to control xol-1 transcription and thereby determine C. elegans sex. Molecular rivalry at the xol-1 promoter between XSE transcriptional repressors (the ONECUT homeodomain protein CEH-39 and the NHR SEX-1) and ASE transcriptional activators (the T-box transcription factor SEA-1 and the zinc finger protein SEA-2) leads to high xol-1 transcript levels in XO embryos with one dose of XSEs and low levels in XX embryos with two doses of XSEs. The RNA-binding protein FOX-1, an XSE, then enhances the fidelity of the counting process in by blocking proper RNA splicing of the sixth intron (yellow) in a dose-dependent manner, resulting in xol-1 mRNA splice variants with in-frame stop codons. High XOL-1 protein levels in XO animals induce male development, and low XOL-1 levels in XX animals induce hermaphrodite development, including loading of the DCC onto X.

a wild-type xol-1 transgene (Fig. 7C). These results show that the XSE- and ASE-binding sites identified by in vitro binding studies are critical for the regulation of xol-1 in vivo. Thus, XSEs and ASEs oppose each other to transmit the X:A signal by regulating xol-1 transcription directly but in opposite ways.

\section{Discussion}

Sex is determined in many organisms by a chromosomecounting mechanism that distinguishes one $\mathrm{X}$ chromosome from two. Here we dissected one such precise counting mechanism in molecular detail to understand how small changes in the concentrations of molecular signals can be translated into different developmental fates. Rather than counting the absolute number of $\mathrm{X}$ chromosomes, the nematode $C$. elegans assesses the number of $\mathrm{X}$ chromosomes relative to the sets of autosomes. We showed previously that a set of genes on $\mathrm{X}$, called XSEs, communicates the embryo's X-chromosome dose by repressing the activity of the master sex-determining gene xol-1 in a cumulative, dose-dependent manner. xol-1 is active and induces the male fate in embryos with one dose of XSEs (1X:2A) but is repressed in embryos with two doses of XSEs (2X:2A), permitting the hermaphrodite fate. Here we identified elements of the autosomal signal and showed that the dose of autosomes is communicated by a corresponding set of ASEs that act in a cumulative, dose-dependent manner to counter XSEs by stimulating xol-1 transcription. We further showed that XSEs and ASEs bind directly to the 5' regulatory region of xol-1 to antagonize each other's activities and thereby set the level of xol-1 transcription to reflect the X:A sex determination signal (Fig. 8). Hence, multiple antagonistic molecular interactions carried out on a single promoter form the basis of the primary sex determination decision in $C$. elegans and make the sex determination process highly responsive to the relative dose of $\mathrm{X}$ chromosomes and autosomes (Fig. 8).

Of the XSEs, the NHR SEX-1 and the ONECUT homeodomain protein $\mathrm{CEH}-39$ bind directly to five non-overlapping cis-acting regulatory sites on the xol-1 promoter and gene body to repress transcription. SEX-1-binding sites resemble canonical NHR sites, and CEH-39-binding sites resemble canonical ONECUT homeodomain sites. Disrupting all SEX-1 and CEH-39 sites on a Xol-1 transgene in vivo recapitulated the derepression of xol-1 and consequent XX lethality caused by disrupting the respective XSE genes. This XX lethality was rescued by mutations in the ASEs sea-1, which encodes a T-box transcription factor, and sea-2, which encodes a zinc finger protein, establishing that SEX-1 and CEH-39 repress xol-1 directly by binding to it.

SEA-1 also binds directly to five sites on the xol-1 promoter and gene body. While SEA-1 can bind to canonical T-box sites in vitro, the xol-1 sites are variable in 
length and do not resemble canonical T-box-binding sites, suggesting that it belongs to a different class of T-box transcription factors. Disrupting the SEA-1-binding sites on a xol-1 transgene also reiterated the effects of knocking out the endogenous sea-1 gene. The binding site mutations partially suppressed the XX lethality caused by a sex-1-null mutation or the fox-1 sex-1 double-mutant combination, confirming that SEA-1 binds directly to xol-1 to stimulate its transcription. While the purified SEA-2 protein failed to bind xol-1 DNA in vitro, SEA-2 did bind in vivo to multiple sites on the xol-1 promoter and gene body, indicating that SEA-2 activates xol-1 transcription directly.

The autosomal signal also includes the ASE sea-3, which collaborates with sea-1 and sea-2 to oppose XSEs and thereby promote the male fate. Its molecular cloning has not yet been achieved. Disrupting all three sea genes suppresses the XX lethality caused by loss of XSEs significantly more than just disrupting sea-1 and sea-2. Furthermore, disrupting all three sea genes reduced the autosomal signal sufficiently to kill males due to inadequate activation of xol-1. Hence, these three elements function together as strong xol-1 activators. Nevertheless, the fact that some triple-mutant $\mathrm{XO}$ animals survive reveals that additional ASEs must contribute to the autosomal signal. Our screen likely failed to identify other ASEs because Mos1 has a 30\% average transposition frequency (Williams et al. 2005), and only 9400 mutagenized haploid genomes were screened.

A prior study demonstrated that sex-1 promotes the hermaphrodite fate by acting in two capacities: as an XSE to repress xol-1 and as an activator of hermaphroditepromoting genes that function downstream from xol-1 to activate dosage compensation (Gladden et al. 2007). sex-1 exerts the majority of its sex-determining function through xol-1. Similarly, our study demonstrated that sea-1 and sea-2 function in two capacities to control the male modes of sex determination and dosage compensation: as an ASE to activate xol-1 and as a repressor of hermaphrodite-promoting activity that acts downstream from xol-1. Like sex-1, both sea-1 and sea-2 exert the majority of their sex-determining function by acting on xol-1. We note, though, that sea-2 has roles in development beyond controlling sex determination and dosage compensation. Huang et al. (2011) demonstrated a role for sea-2 in regulating larval developmental timing and adult life span.

The worm X:A-counting mechanism fits Bridges' 1921 textbook paradigm for fly sex determination, but the fly mechanism does not

While our study shows that the worm X:A-sensing process fulfills Bridges' proposed model for fly sex determination involving a set of feminizing genes on $\mathrm{X}$ and an antagonistic set of masculinizing genes on autosomes (Fig. 8; Bridges 1921), others have shown recently that the fly X:A-sensing process does not (Barbash and Cline 1995; Erickson and Quintero 2007). In the fruit fly, the target of the X:A signal is $S x l$ (sex-lethal), a sex-determining switch gene that induces female development when active and male development when inactive /Cline and Meyer 1996). A set of feminizing XSEs communicates X-chromosome number (Cline 1988; Erickson and Cline 1991, 1993; Sefton et al. 2000) by activating Sxl transcription in a dose-dependent manner. The double dose of XSEs in 2X:2A embryos turns $\mathrm{Sxl}$ on, while the single dose in 1X:2A embryos does not. In contrast, ploidy appears not to be signaled by a corresponding set of masculinizing autosomal genes (Barbash and Cline 1995; Erickson and Quintero 2007). Instead, the effect of ploidy in this dosesensitive process is indirect, influencing the timing of cellularization during early development and thereby the length of time during which XSE protein can increase in concentration to reach the threshold necessary to activate Sxl (Erickson and Quintero 2007). The lower the ploidy, the later the embryos cellularize, the longer the XSEs can accumulate, and the higher the probability of activating $S x l$. As a consequence, 1X:1A embryos become females instead of males, and 2X:3A embryos become mosaic intersexes. Only a single fly ASE was identified through extensive genetic screens to identify suppressors of XSE mutations (Barbash and Cline 1995). That ASE acts as a weak transcriptional repressor of $S \times l$ and is thought to function relatively late to fine-tune the counting process in diploids.

\section{Models for antagonistic molecular interactions between worm XSES and ASES}

Given the numerous binding sites for XSEs and ASEs on the xol-1 gene, how do these signal elements counteract each other to promote opposite transcriptional states? The findings that XSE- and ASE-binding sites are distinct and nonoverlapping and that SEX-1 and SEA-1 can bind simultaneously to the same DNA fragment suggest that direct competition for binding to xol-1 is not likely to underlie the antagonistic molecular interactions between these XSEs and ASEs at the xol-1 promoter. Instead, because nuclear receptors, ONECUT homeobox proteins, and T-box proteins repress or activate transcription by tethering corepressors or coactivators to their gene targets (Asahara et al. 1999; Maira et al. 2003; Privalsky 2004; Murakami et al. 2005), an attractive alternative model is that XSEs and ASEs recruit cofactors with reciprocal enzymatic activities to the xol-1 promoter to elicit opposite transcriptional states. Common cofactors are those that modify histones to regulate transcription, including histone acetyltransferases and methyltransferases for gene activation and histone deacetylases for gene repression (Privalsky 2004; Lee et al. 2005a,b).

Our identification here of the true xol-1 TSS revealed that the $5^{\prime}$ region with the highest density of SEX-1-, CEH-39-, and SEA-1-binding sites overlaps the -1 nucleosome, which carries post-translational modifications positively correlated with xol-1 activity (Supplemental Fig. S5A-C). In young embryos, when xol-1 is active prior to its repression by XSEs, the nucleosome carries the H3K4me3 and H3K27ac modifications typical of transcribed genes. Nucleosomes in the gene body also carry modifications typical of transcription elongation: H3K79me3 and 
H3K36me3. All four modifications are absent later in development, when xol-1 is repressed. Regulation of the post-translational modification of the -1 nucleosome by ASEs and XSEs is a highly plausible mechanism for at least part of the antagonism between XSEs and ASEs.

T-box proteins can trigger the acetylation of histones and achieve transcriptional activation during development. For example, the T-box transcription factor TBX5 plays an essential, dose-dependent role in both cardiac and limb development (Mori and Bruneau 2004; Murakami et al. 2005). As with sea-1, the TBX5 gene is haploinsufficient. Patients with Hold-Oram syndrome carry heterozygous mutations in TBX5 and have defects in their heart and upper extremities. TBX5 recruits the coactivator TAZ to stimulate transcription of TBX5-dependent promoters by tethering the histone acetyltransferase proteins p300 and PCAF to the TBX5-binding sites. Similarly, NHRs such as SEX-1 are known to tether histone deacetylases and histone demethylases to their binding sites through corepressors to repress transcription (Privalsky 2004; Rosenfeld et al. 2006; Cai et al. 2011).

In our model, ASEs such as SEA-1 and SEA-2 would accumulate in high concentration at the xol-1 promoter of young embryos to activate transcription in part by catalyzing the acetylation of the -1 nucleosome. In embryos with a double dose of XSEs, sufficient XSE protein would accumulate on the xol-1 promoter over time to repress transcription in part by catalyzing the deacetylation of the -1 nucleosome and perhaps the demethylation of nucleosomes in the gene body. This type of molecular antagonism requires that ASEs and XSEs accumulate on the xol-1 promoter at overlapping times, when the $\mathrm{X}$ :A signal is being assessed. Two lines of evidence support this condition. Both SEA-1 and SEX-1 can bind together in vitro to a single fragment of xol-1 DNA that encodes the highest density of XSE- and ASE-binding sites. Also, SEX-1 and SEA-2 colocalize with xol-1 regulatory regions in vivo at overlapping times, from at least the 20-cell stage when xol-1 is active until after the 60-cell stage, when xol-1 expression becomes significantly repressed.

The competing mechanisms of xol-1 activation and repression need not be limited to the regulation of histone modification at the TSS. In general, corepressors recruited by NHRs and ONECUT homeodomain proteins can make inhibitory contacts directly with the basal transcription machinery to limit transcription (Baniahmad et al. 1993; Muscat et al. 1998; Wong and Privalsky 1998), and coactivators recruited by T-box proteins can make productive contacts with the basal machinery to stimulate transcription (Kwok et al. 1994; Yao et al. 1996; Maira et al. 2003). The locations of ASE- and XSE-binding sites throughout the promoter and first part of the gene are well positioned to permit such direct inhibitory and stimulatory contacts with the transcription machinery.

\section{Synergy in XSE action}

The high degree of specificity for SEX-1 and CEH-39 in sex determination cannot be explained completely by the 6-bp response elements within the XSE-binding sites. The elements by themselves are too short to confer strong stability in XSE binding to xol-1. Binding is likely enhanced through the association of XSEs with each other or with other more general DNA-binding proteins. Given that XSEs function cumulatively and mutations in sex-1 and ceh-39 act synergistically, the possibility existed that SEX-1 and CEH-39 might bind to xol-1 cooperatively, and the cooperativity might help the stability and specificity. However, in vitro binding studies of SEX-1 and CEH-39 to probes with neighboring NHR- and ONECUT-binding sites failed to demonstrate cooperative binding in gel shift assays (data not shown).

NHRs and homeodomain proteins commonly bind target genes as homodimers or as heterodimers with proteins of their respective class via closely spaced response elements (Mangelsdorf et al. 1995). Dimerization enhances the stability and specificity in binding. However, the two closest SEX-1 response elements are 48 bp apart with no NHR recognition elements nearby, and the closest CEH-39 response elements are 308 bp apart, suggesting that SEX-1 and CEH-39 bind xol-1 as monomers. SEX-1 and CEH-39 are thus likely to associate with other unidentified transcription factors or with corepressors tethered to other DNA-binding proteins that confer increased binding stability by contributing additional contacts with DNA. The synergy between SEX-1 and CEH-39 in repressing xol-1 transcription would then derive from the aggregate effect of XSEs making multiple independent contacts with xol-1 regulatory sequences to elicit inhibitory contacts with the basal transcription machinery through corepressors and/or to recruit corepressors with the same or different enzymatic activities to repress transcription in part by altering nucleosome post-translational modification. To date, only a single NHR corepressor molecule (DIN-1) has been identified functionally in C. elegans (Ludewig et al. 2004), and we found that it does not function in the sex determination pathway (data not shown).

Although transcriptional repression is the predominant form of xol-1 regulation by XSEs, they also repress xol-1 through a post-transcriptional mechanism. The XSE FOX-1 binds the sixth intron of xol-1 pre-mRNA and thereby blocks productive xol-1 mRNA splicing, generating an in-frame stop codon (C Pickle, M Nicole, and BJ Meyer, in prep.). This splicing control enhances the fidelity of the counting process once the transcriptional regulation has occurred (Fig. 8). fox-1 mutations cause no $\mathrm{XX}$-specific lethality by themselves but cause synergistic lethality in combination with sex-1 mutations.

\section{Another influence on the target of the X:A signal?}

A negative regulatory feedback loop has been proposed to repress xol-1 by the terminal feminizing switch gene in the sex determination regulatory hierarchy tra-1 (Hargitai et al. 2009). The TRA-1 zinc finger protein represses male differentiation genes and induces hermaphrodite differentiation genes. The loop is proposed to function after $\mathrm{X}$ :A assessment, perhaps to maintain a low xol-1 activity state in XX embryos once the major sex determination decision has been made and sexual differentiation is 
under way. Partial loss of tra-1 was reported to cause significant XX lethality that could be suppressed by mutations in xol-1. A TRA-1-binding site was found in xol-1 at +1045 with respect to our new TSS. We investigated the contribution of tra-1 to the repression of xol-1 and found the contribution to be minimal compared with that reported by Hargitai et al. (2009) (Supplemental Fig. 11). We found that complete loss of tra-1 caused very little XX lethality under standard growth conditions, and none of the lethality was suppressible by a xol-1-null mutation, indicating that misregulation of xol-1 was not the cause of lethality. We did find some xol-1-suppressible lethality under more extreme growth conditions but less than reported previously, and the escapers had no dosage compensation defects, unlike XSE mutants. Hence, a repressive interaction between tra-1 and xol-1 is unlikely to constitute a significant feedback loop.

\section{Implications of the X:A signal for development and disease}

The classes of regulatory molecules that play critical roles in the X:A-sensing process-NHRs, ONECUT homeodomain proteins, and T-box proteins-also have central roles in development, homeostasis, and reproduction, even in humans. For all of these functions, the dose sensitivity of genes encoding the regulatory molecules underlies the pathologies and developmental disorders. As examples, haploinsufficiency of the nuclear receptor steroidogenic factor (SF-1) causes XY sex reversal and adrenal failure in humans (Achermann et al. 1999; Bland et al. 2000); haploinsufficiency of the T-box gene $T B \times 1$ causes DiGeorge syndrome, characterized by cardiovascular, thymus, and craniofacial anomalies (Lindsay et al. 2001; Baldini 2006); and haploinsufficiency of the homeobox gene Pitx2 causes Rieger syndrome type 1, characterized by ocular, dental, abdominal, and craniofacial malformation (Flomen et al. 1998; Liu et al. 2003). The underlying molecular defects triggered from inappropriate gene dose are not known for these human diseases, but advances in our molecular understanding of the $\mathrm{X}$ :A-sensing process in C. elegans provide a guide for future investigations.

\section{Materials and methods}

\section{Isolation of sea-2 alleles}

For each ASE screen, the final mutagenesis strain fox-1 sex-1; yEx 660; oxEx229 was created by crosses using two initial strains (see Fig. 1B): (1) a fox-1 sex-1 XX strain carrying the transgenic extrachromosomal array yEx660 [dpy-30::sdc-2(+) (30 ng/ $\mathrm{LL})$, hsp-16-48::Mos1 transposase (10 ng/mL), unc-122::gfp (30 ng/ $\mathrm{mL})$, and genomic DNA (200 $\mathrm{ng} / \mu \mathrm{L})]$ and (2) a strain carrying oxEx229 (Mos1, myo-2::gfp) (Bessereau et al. 2001). All crosses were performed at $25^{\circ} \mathrm{C}$ to prevent germline silencing of the arrays. Approximately 50 double-transgenic animals were subjected to heat shock per screen as follows: $1 \mathrm{~h}$ at $33^{\circ} \mathrm{C}, 1 \mathrm{~h}$ of recovery at $15^{\circ} \mathrm{C}, 1 \mathrm{~h}$ at $33^{\circ} \mathrm{C}$, and $20 \mathrm{~h}$ of recovery at $15^{\circ} \mathrm{C}$. $\mathrm{F} 1$ progeny were examined by PCR to determine Mos 1 transposition frequency per screen $(30 \%-40 \%)$. We obtained 619 viable nongreen hermaphrodites from F2 progeny representing 9400
Mos1 mutagenized haploid genomes. Only 120 of 619 produced viable F3 progeny, and only 30 of 120 contained the Mos1 transposon. Mos1-containing strains were outcrossed at least four times, and only five of 30 strains had the transposon linked to the suppression phenotype. The transposon insertion site was identified in each strain by inverse PCR as described in Bessereau et al. (2001). For each insertion allele, the corresponding ORF was disrupted by RNAi in a fox-1 sex-1 double mutant. RNAi of only K10G6.3 phenocopied the suppression of fox-1 sex-1 lethality to the same degree as the corresponding insertion allele. This screen yielded sea-2(y407), which has a Mos1 insert in exon 4 but is not a null allele. A sea-2-null allele was obtained by excising the Mos1 transposon from sea-2(y407), and sea-2(y410) was isolated from a deletion library (see the Supplemental Material).

\section{Genetic analysis and phenotypic characterization}

Hermaphrodite viability was assessed by picking one to three L4 larvae per plate, serially transferring animals every $24 \mathrm{~h}$ for $2-3 \mathrm{~d}$, counting the number of embryos and L1s after transfer, and counting the total adults $4-5 \mathrm{~d}$ after plating the original L4s. Percent viability was calculated as [(total number of adults)/ [total number of embryos)] $\times 100$.

The effects of changing sea-2 activity on the viability of males with an extra copy of both ceh-39 and fox-1 (on yDp14 X:I) was assessed by either crosses or analysis of strains carrying him8(e1489). (1) To assess the viability of $y D p 14 /+$ males (Fig. 2C), wild-type males were crossed with yDp14 X:I; rol-6(e187) II; unc2(e55) $X$, and the non-Rol cross progeny $(y D p 14 /+;$ rol-6/+; unc-2/+ $\mathrm{XX}$ or $\mathrm{y} D \mathrm{p} 14 /+$; rol-6/+); unc-2 XO animals were counted. Percent male viability was calculated by the formula [/total number of males observed)/(total number of males expected)] $\times$ 100 , where the expected male frequency is equal to the number of hermaphrodite cross progeny observed. (2) To assess the viability of sea-2(y426)/+; yDp14/+ males (Fig. 2C), sea-2(y426) males were crossed with yDp14 X:I; rol-6(e187 II); unc-2(e55) X hermaphrodites, and progeny were analyzed as above. Surviving heterozygous male cross progeny $[y D p 14 /+$; sea-2(y426)/rol6(e187); unc-2(e55)] were crossed back to $y D p 14$; rol-6(e187); unc-2(e55) hermaphrodites to create homozygous $y \mathrm{Dp} 14$; sea2(y426); unc-2 hermaphrodites. (3) To assess the viability of sea-2(y426)/sea-2(y426); yDp14/+ males (Fig. 2C), sea-2(y426) males were crossed with yDp14; sea-2(y426); unc-2 hermaphrodites, and cross progeny were analyzed as above. (4) To assess the viability of $y D p 14 /+;$ sea-2(y407)/+ males and $y D p 14 /+; y I s 57$ [sea-2(+)] males (Fig. 2E), progeny from the him-8(e1489) strains were analyzed as follows. For $y D p 14 /+$ male viability, the relative number of $y D p 14 /+$; him-8(e1489); unc-2(e55) (nonUnc) and +/+; him-8(e1489); unc-2(e55) (Unc) male self-progeny were counted from yDp14/+; him-8(e1489); unc-2(e55) hermaphrodites. Of the male progeny, one-fourth are expected to be Unc; one-fourth are expected to die (yDp14 homozygotes), and one-half are expected to be non-Unc. Percent male viability was calculated as [(total number of non-Unc males observed)/ (total number of non-Unc males expected)] $\times 100$, where the number of expected males is equal to two times the number of Unc males observed. Self-progeny from yDp14/+; sea-2(y407); him-8(e1489); unc-2(e55), and yDp14/+; yIs57 him-8(e1489); unc-2(e55) hermaphrodites were counted as above. yDp14/+ male viability is typically higher in the progeny of homozygous him-8(1489) hermaphrodites than in the progeny from crosses.

\section{SEA-2 antibody}

Rabbit anti-SEA-2 antibodies were raised and affinity-purified against a C-terminal 21-amino-acid peptide (CG-linker)RMA 
Farboud et al.

DQFMMNTNYTTPPTHVQL. Embryos were fixed and stained as described (Powell et al. 2005).

\section{xol-1 reporter assay}

The integrated transgenic reporter yIs33(Pxol-1::1acZ) used to assess $\beta$-galactosidase activity in $\mathrm{XO}, \mathrm{XX}$, and sea-2-overexpressing (yIs57) embryos at $20^{\circ} \mathrm{C}$ or $25^{\circ} \mathrm{C}$ contains 1633 bp of xol-1 regulatory sequences upstream of the TSS and 1203 bp between the TSS and the TSL site, which was fused to the lacZ ORF and 3' unc-54 untranslated region (UTR) (Nicoll et al. 1997). Worms were grown for two generations at each temperature, and gravid adults were fixed and stained as described (Fire 1992). Embryo staining was examined using differential interference contrast (DIC) microscopy, and $>600$ embryos were examined from $>50$ hermaphrodites for each genotype. Embryos were classified as having no (or weak), moderate, or high staining.

\section{Protein expression and purification}

SEX-1 was expressed in Sf-9 cells using the Bac-to-Bac Baculovirus Expression system (Invitrogen) and nuclear extracts prepared as described (Chen et al. 1993), with the exception that the hypertonic buffer was supplemented with $0.8 \mathrm{mM} \mathrm{KCl}$ and $1 \%$ NP-40. For control nuclear extracts, nonrecombinant baculovirus was used to infect Sf-9 cells, and nuclear extracts were prepared as above. Protein expression was examined by SDSPAGE/Western blotting and Coomassie staining, and protein concentrations were determined by Bradford assay (Thermo Scientific).

Full-length SEA-1 encoding cDNA was cloned into pGEX-4T (GE Biosciences) as an N-terminal GST fusion expression construct and expressed in BL21 cells (Smith and Johnson 1988). Cells were induced with IPTG for $2 \mathrm{~h}$ at $37^{\circ} \mathrm{C}$, and protein was extracted. Cells were resuspended in STE buffer $(150 \mathrm{mM} \mathrm{NaCl}$, $10 \mathrm{mM}$ Tris at $\mathrm{pH}$ 8.0, $1 \mathrm{mM}$ EDTA) supplemented with $100 \mu \mathrm{g} /$ $\mathrm{mL}$ lysozyme, $3 \mathrm{mM}$ DTT, $1.5 \mathrm{mM}$ PMSF, and $1 \%$ Triton X-100, incubated on ice for $20 \mathrm{~min}$, frozen in liquid nitrogen, and thawed immediately at room temperature. The homogenate was then supplemented with $0.8 \mathrm{M} \mathrm{NaCl}, 0.5 \% \mathrm{NP}-40$, and $5 \mathrm{mM}$ DTT and sonicated. Cleared supernatant was then incubated with glutathione agarose in STE buffer and washed in a stepwise fashion in STE buffer supplemented with $500 \mathrm{mM} \mathrm{NaCl}$ and STE buffer supplemented with $250 \mathrm{mM} \mathrm{NaCl}$, and bound protein were eluted. GST was purified in an identical manner using the empty pGEX-4T3 vector. All steps of the purifications were assessed on a $10 \%$ acrylamide gel (37.5:1) by Coomassie staining, and protein concentrations were determined by Bradford assay.

CEH-39 was expressed using the TNT Quick-Coupled Transcription/Translation system (Promega). Full-length CEH-39 cDNA was cloned into pSG5 (Stratagene), and $1 \mu \mathrm{g}$ of plasmids was used per $50-\mu \mathrm{L}$ reaction. Protein expression was confirmed using SDS-PAGE/Western blotting. For controls, $1 \mu \mathrm{g}$ of empty pSG5 vector was used to prime the reactions.

\section{EMSAs}

dsDNA probes of $\sim 300$ bp were generated by PCR using oligonucleotides engineered to have unique Age1 sites. Probes were digested with Age1 (New England Biolabs), purified over QiaQuick Gel Extraction columns (Qiagen), and radiolabeled by Klenow polymerase fill-in using ${ }^{32} \mathrm{P}-\alpha$-dGTP $(3000 \mathrm{Ci} / \mathrm{mmol})$ (PerkinElmer). Labeled double-stranded probes were extracted after PAGE. For each binding reaction, $10 \mathrm{nM}$ final probe concentration $(50,000$ counts per minute [cpm]) was used in binding buffer $1\{10 \mathrm{mM}$ Tris-Cl at $\mathrm{pH} 7.5,2 \mathrm{mM} \mathrm{MgCl} 2,250 \mathrm{mM} \mathrm{KCl}$,
$5 \mathrm{mg} / \mathrm{mL}$ BSA, $100 \mathrm{ng} / \mu \mathrm{L}$ poly deoxyinosinic-deoxycytidylic acid [poly(dI.dC)]]. For binding of SEX to the 300-mer probes, binding buffer 1 was supplemented with $160 \mathrm{ng} / \mu \mathrm{L}$ poly(dI.dC). For shorter probes, commercially prepared oligonucleotides were synthesized, annealed, and radioactively labeled as above. After labeling, unincorporated nucleotides were removed by separation over a Sephadex G-50 quick-spin column (GE Biosciences). For binding to the shorter probes, $100 \mathrm{nM}$ final probe concentration was used, possessing $250,000 \mathrm{cpm}$ in binding buffer $2[10$ $\mathrm{mM}$ Tris-Cl at $\mathrm{pH} 7.5,2 \mathrm{mM} \mathrm{MgCl} 2,50 \mathrm{mM} \mathrm{KCl}, 2.5 \mathrm{mg} / \mathrm{mL}$ BSA, $20 \mathrm{ng} / \mu \mathrm{L}$ poly $(\mathrm{dI} \cdot \mathrm{dC})]$.

For probes of all lengths, binding reactions were supplemented with $150 \mathrm{ng}$ of GST or GST-SEA-1 that had been diluted in nuclear extract dilution (NED) buffer (20 mM HEPES at $\mathrm{pH} 7.9$, $10 \%$ glycerol, $300 \mathrm{mM} \mathrm{KCl}, 10 \mathrm{mg} / \mathrm{mL}$ BSA, $1 \mathrm{mM} \mathrm{DTT}), 20 \mathrm{ng}$ of Sf-9 nuclear extract infected with nonrecombinant baculovirus or infectected with baculovirus encoding SEX-1 in NED buffer, or $2 \mu \mathrm{L}$ of reticulocyte lysate primed with empty vector or primed with a CEH-39 expression vector. Binding reactions were performed for $15 \mathrm{~min}$ at room temperature and resolved on a $5 \%$ acrylamide $(29: 1) / 0.5 \times \mathrm{TBE}$ gel for $2 \mathrm{~h}$ at $180 \mathrm{~V}$. The gel was dried, exposed to a PhosphorImager screen, and analyzed using a Typhoon PhosphorImager (GE Biosciences). To assess CEH-39 binding to 300-mer probes, the amount of protein-bound probe was quantified. To assess SEX-1 binding, the amount of unbound probe remaining per reaction was quantified. For binding to smaller probes, the amount of protein-bound probe was analyzed for all proteins.

\section{DNase I footprinting assay}

xol-1 promoter fragments were PCR-amplified and cloned into pUC19 using the restriction endonucleases EcoRI and BamHI and sequenced. The resulting plasmid was first digested with EcoRI (forward strand) or BamHI (reverse strand), treated with calf intestinal phosphatase (New England Biolabs), and phenol/ chloroform-extracted. Five micrograms of the purified DNA was labeled with $300 \mu \mathrm{Ci}{ }^{32} \mathrm{P}-\gamma$-dATP (MP Biomedicals) using T4 polynucleotide kinase (New England Biolabs), and unincorporated bases were removed with Sephadex G-50. Fragments were digested with BamHI enzyme (forward strand) or EcoRI enzyme (reverse strand), and labeled fragments were PAGE-purified. A DNase I footprinting assay was performed by incubating a ${ }^{32} \mathrm{P}$ labeled probe $(\sim 1000 \mathrm{cpm})$ with $2 \mu \mathrm{L}$ of nuclear extract dilution buffer; $600 \mathrm{ng}$ of GST or $600 \mathrm{ng}$, $300 \mathrm{ng}$, $150 \mathrm{ng}$, or $75 \mathrm{ng}$ of GSTSEA-1 on ice for $20 \mathrm{~min}$ in $5 \%$ glycerol; $37.5 \mathrm{mM} \mathrm{KCl} ; 0.5 \mathrm{mM}$ EDTA; 0.5 mM EGTA; 12.5 mM HEPES (pH 7.6); $25 \mu \mathrm{g} / \mathrm{mL}$ BSA; $0.1 \mathrm{mM}$ PMSF; and $0.5 \mathrm{mM} \mathrm{DTT}$ in a total volume of $45 \mu \mathrm{L}$. After incubation, the samples were treated with 2 ng of DPFF grade DNaseI (Worthington) for $1 \mathrm{~min}$ at room temperature. The samples were then phenol/chloroform-extracted, ethanol-precipitated, and resolved on an $8 \%$ acrylamide/8 $\mathrm{M}$ urea sequencing gel in $1 \times$ TBE buffer. A sequencing ladder was made by treating a sample of the probe with formic acid and piperidine to cleave at A and G residues (Maxam and Gilbert 1977). The DNase I footprinting assay was visualized on a Typhoon PhosphorImager.

\section{SEA-2 in vivo binding assays on xol-1}

Array-bearing embryos carrying either the entire xol-1 promoter, subregions of the promoter, exons, or control sequences lacking xol-1 (Fig. 4D) were fixed and stained as described (Carmi et al. 1998). Array strains were made by transforming wild-type animals with a mixture of plasmid or PCR products that possess xol-1 sequence $(10 \mathrm{ng} / \mu \mathrm{L})$, pTY1604 (lacO repeat; $50 \mathrm{ng} / \mu \mathrm{L}$ ), pTY1605 (lacI::gfp; $50 \mathrm{ng} / \mu \mathrm{L}$ ), and pPD118.33 (Pmyo-2::gfp; $5 \mathrm{ng} / \mu \mathrm{L})$. 


\section{Generation and analysis of xol-1 transgenic strains}

xol-1 transgenes lacking XSE- or ASE-binding sites were constructed as described in the Supplemental Material. Numerous transgenic lines were generated for each wild-type or mutant transgene, and quantitative PCR (qPCR) was performed to assess the copy number of the integrated transgenes once they were crossed into xol-1(null) hermaphrodites. Transgenes were then crossed into appropriate XSE and ASE mutant backgrounds to analyze the importance of the ASE- and XSE-binding sites in xol-1 regulation. All transgenic strains were maintained on xol-1(RNAi) feeding bacteria to prevent the misregulation of xol-1 from killing the animals. To determine the viability of the strains, embryos were transferred from RNAi plates to standard NGM plates with OP50 bacteria and grown for two generations prior to assessing the viability of progeny from L4 hermaphrodites.

\section{Acknowledgments}

We thank J. Powell for the isolation of sea-3; W. Kruesi for assistance in analyzing modENCODE data; the Caenorhabditis Genetics Center; the Gene Knockout Consortium, and the National Bioresource Project for strains; T. Cline and B. Wheeler for critical comments on the manuscript; and J. Gardner and D. Stalford for assistance with figures. This work was supported by $\mathrm{NIH}$ grant R01-GM30702. B.F. was supported by American Cancer Society Post-doctoral Fellowship PF-06-027-01-DCC, and M.M.J. was supported by $\mathrm{NIH}$ training grant T32-GM07127. B.J.M. is an investigator of the Howard Hughes Medical Institute.

\section{References}

Achermann JC, Ito M, Ito M, Hindmarsh PC, Jameson JL. 1999. A mutation in the gene encoding steroidogenic factor-1 causes XY sex reversal and adrenal failure in humans. Nat Genet 22: 125-126.

Akerib CC, Meyer BJ. 1994. Identification of X chromosome regions in Caenorhabditis elegans that contain sex-determination signal elements. Genetics 138: 1105-1125.

Asahara H, Dutta S, Kao HY, Evans RM, Montminy M. 1999. Pbx-Hox heterodimers recruit coactivator-corepressor complexes in an isoform-specific manner. Mol Cell Biol 19: 8219-8225.

Baldini A. 2006. The 22q11.2 deletion syndrome: A gene dosage perspective. ScientificWorldJournal 6: 1881-1887.

Baniahmad A, Ha I, Reinberg D, Tsai S, Tsai MJ, O'Malley BW. 1993. Interaction of human thyroid hormone receptor $\beta$ with transcription factor TFIIB may mediate target gene derepression and activation by thyroid hormone. Proc Natl Acad Sci 90: $8832-8836$

Barbash DA, Cline TW. 1995. Genetic and molecular analysis of the autosomal component of the primary sex determination signal of Drosophila melanogaster. Genetics 141: 1451-1471.

Bessereau JL, Wright A, Williams DC, Schuske K, Davis MW, Jorgensen EM. 2001. Mobilization of a Drosophila transposon in the Caenorhabditis elegans germ line. Nature 413: 70-74.

Bland ML, Jamieson CA, Akana SF, Bornstein SR, Eisenhofer G, Dallman MF, Ingraham HA. 2000. Haploinsufficiency of steroidogenic factor-1 in mice disrupts adrenal development leading to an impaired stress response. Proc Natl Acad Sci 97: 14488-14493.

Bridges CB. 1921. Triploid intersexes in Drosophila Melanogaster. Science 54: 252-254.

Bull JJ. 1983. Evolution of sex determining mechanisms. The Benjamin/Cummings Publishing Co, Inc., Menlo Park, CA.
Cai C, He HH, Chen S, Coleman I, Wang H, Fang Z, Chen S, Nelson PS, Liu XS, Brown M, et al. 2011. Androgen receptor gene expression in prostate cancer is directly suppressed by the androgen receptor through recruitment of lysine-specific demethylase 1. Cancer Cell 20: 457-471.

Carmi I, Kopczynski JB, Meyer BJ. 1998. The nuclear hormone receptor SEX-1 is an X-chromosome signal that determines nematode sex. Nature 396: 168-173.

Casey ES, O'Reilly MA, Conlon FL, Smith JC. 1998. The T-box transcription factor Brachyury regulates expression of eFGF through binding to a non-palindromic response element. Development 125: 3887-3894.

Charlesworth D, Mank JE. 2010. The birds and the bees and the flowers and the trees: Lessons from genetic mapping of sex determination in plants and animals. Genetics 186: 9-31.

Chen H, Smit-McBride Z, Lewis S, Sharif M, Privalsky ML. 1993. Nuclear hormone receptors involved in neoplasia: erb A exhibits a novel DNA sequence specificity determined by amino acids outside of the zinc-finger domain. Mol Cell Biol 13: 2366-2376.

Chuang PT, Albertson DG, Meyer BJ. 1994. DPY-27: A chromosome condensation protein homolog that regulates C. elegans dosage compensation through association with the $\mathrm{X}$ chromosome. Cell 79: 459-474.

Cline TW. 1988. Evidence that sisterless-a and sisterless-b are two of several discrete 'numerator elements' of the X/A sex determination signal in Drosophila that switch Sxl between two alternative stable expression states. Genetics 119: 829862.

Cline TW, Meyer BJ. 1996. Vive la difference: Males vs females in flies vs worms. Annu Rev Genet 30: 637-702.

Dawes HE, Berlin DS, Lapidus DM, Nusbaum C, Davis TL, Meyer BJ. 1999. Dosage compensation proteins targeted to X chromosomes by a determinant of hermaphrodite fate. Science 284: 1800-1804.

Erickson JW, Cline TW. 1991. Molecular nature of the Drosophila sex determination signal and its link to neurogenesis. Science 251: 1071-1074.

Erickson JW, Cline TW. 1993. A bZIP protein, sisterless-a, collaborates with bHLH transcription factors early in Drosophila development to determine sex. Genes Dev 7: 1688-1702.

Erickson JW, Quintero JJ. 2007. Indirect effects of ploidy suggest $\mathrm{X}$ chromosome dose, not the $\mathrm{X}: \mathrm{A}$ ratio, signals sex in Drosophila. PLoS Biol 5: e332.

Fire A. 1992. Histochemical techniques for locating Escherichia coli $\beta$-galactosidase activity in transgenic organisms. Genet Anal Tech Appl 9: 151-158.

Flomen RH, Vatcheva R, Gorman PA, Baptista PR, Groet J, Barisic I, Ligutic I, Nizetic D. 1998. Construction and analysis of a sequence-ready map in 4q25: Rieger syndrome can be caused by haploinsufficiency of RIEG, but also by chromosome breaks approximately $90 \mathrm{~kb}$ upstream of this gene. Genomics 47: 409-413.

Gladden JM, Meyer BJ. 2007. A ONECUT homeodomain protein communicates X chromosome dose to specify Caenorhabditis elegans sexual fate by repressing a sex switch gene. Genetics 177: 1621-1637.

Gladden JM, Farboud B, Meyer BJ. 2007. Revisiting the X:A signal that specifies Caenorhabditis elegans sexual fate. Genetics 177: 1639-1654.

Hargitai B, Kutnyanszky V, Blauwkamp TA, Stetak A, Csankovszki G, Takacs-Vellai K, Vellai T. 2009. xol-1, the master sex-switch gene in C. elegans, is a transcriptional target of the terminal sex-determining factor TRA-1. Development 136: 3881-3887.

Herskowitz I. 1989. A regulatory hierarchy for cell specialization in yeast. Nature 342: 749-757. 
Hodgkin J, Zellan JD, Albertson DG. 1994. Identification of a candidate primary sex determination locus, fox-1, on the $\mathrm{X}$ chromosome of Caenorhabditis elegans. Development 120: 3681-3689.

Huang X, Zhang H, Zhang H. 2011. The zinc-finger protein SEA-2 regulates larval developmental timing and adult lifespan in C. elegans. Development 138: 2059-2068.

Iyaguchi D, Yao M, Watanabe N, Nishihira J, Tanaka I. 2007. DNA recognition mechanism of the ONECUT homeodomain of transcription factor HNF-6. Structure 15: 75-83.

Kispert A, Herrmann BG. 1993. The Brachyury gene encodes a novel DNA binding protein. EMBO J 12: 3211-3220.

Kwok RP, Lundblad JR, Chrivia JC, Richards JP, Bachinger HP Brennan RG, Roberts SG, Green MR, Goodman RH. 1994. Nuclear protein CBP is a coactivator for the transcription factor CREB. Nature 370: 223-226.

Lee DY, Teyssier C, Strahl BD, Stallcup MR. 2005a. Role of protein methylation in regulation of transcription. Endocr Rev 26: 147-170.

Lee MG, Wynder C, Cooch N, Shiekhattar R. 2005b. An essential role for CoREST in nucleosomal histone 3 lysine 4 demethylation. Nature 437: 432-435.

Lindsay EA, Vitelli F, Su H, Morishima M, Huynh T, Pramparo T, Jurecic V, Ogunrinu G, Sutherland HF, Scambler PJ, et al. 2001. Tbx1 haploinsufficieny in the DiGeorge syndrome region causes aortic arch defects in mice. Nature 410: 97-101.

Liu W, Selever J, Lu MF, Martin JF. 2003. Genetic dissection of Pitx2 in craniofacial development uncovers new functions in branchial arch morphogenesis, late aspects of tooth morphogenesis and cell migration. Development 130: 6375-6385.

Ludewig AH, Kober-Eisermann C, Weitzel C, Bethke A, Neubert K, Gerisch B, Hutter H, Antebi A. 2004. A novel nuclear receptor/coregulator complex controls C. elegans lipid metabolism, larval development, and aging. Genes Dev 18: 2120-2133.

Luz JG, Hassig CA, Pickle C, Godzik A, Meyer BJ, Wilson IA. 2003. XOL-1, primary determinant of sexual fate in C. elegans, is a GHMP kinase family member and a structural prototype for a class of developmental regulators. Genes Dev 17: 977-990.

Madl JE, Herman RK. 1979. Polyploids and sex determination in Caenorhabditis elegans. Genetics 93: 393-402.

Maira M, Couture C, Le Martelot G, Pulichino AM, Bilodeau S, Drouin J. 2003. The T-box factor Tpit recruits SRC/p160 coactivators and mediates hormone action. I Biol Chem 278: 46523-46532.

Mangelsdorf DJ, Thummel C, Beato M, Herrlich P, Schutz G, Umesono K, Blumberg B, Kastner P, Mark M, Chambon P, et al. 1995. The nuclear receptor superfamily: The second decade. Cell 83: 835-839.

Maxam AM, Gilbert W. 1977. A new method for sequencing DNA. Proc Natl Acad Sci 74: 560-564.

Meyer BJ. 2010. Targeting X chromosomes for repression. Curr Opin Genet Dev 20: 179-189.

Michelitsch MD, Weissman JS. 2000. A census of glutamine/ asparagine-rich regions: Implications for their conserved function and the prediction of novel prions. Proc Natl Acad Sci 97: 11910-11915.

Miller LM, Plenefisch JD, Casson LP, Meyer BJ. 1988. xol-1: A gene that controls the male modes of both sex determination and X chromosome dosage compensation in C. elegans. Cell 55: $167-183$

Mori AD, Bruneau BG. 2004. TBX5 mutations and congenital heart disease: Holt-Oram syndrome revealed. Curr Opin Cardiol 19: 211-215.

Murakami M, Nakagawa M, Olson EN, Nakagawa O. 2005. A WW domain protein TAZ is a critical coactivator for TBX5 a transcription factor implicated in Holt-Oram syndrome. Proc Natl Acad Sci 102: 18034-18039.

Muscat GE, Burke LJ, Downes M. 1998. The corepressor N-CoR and its variants RIP13a and RIP13 1 directly interact with the basal transcription factors TFIIB, TAFII32 and TAFII70. Nucleic Acids Res 26: 2899-2907.

Nicoll M, Akerib CC, Meyer BJ. 1997. X-chromosome-counting mechanisms that determine nematode sex. Nature 388: 200204.

Nigon V. 1951. Polyploidie experimentale chez un nematode libre, Rhabditis elegans Maupas. Bull Biol Fr Belg 85: 187225.

Perry MW, Cande JD, Boettiger AN, Levine M. 2009. Evolution of insect dorsoventral patterning mechanisms. Cold Spring Harb Symp Quant Biol 74: 275-279.

Pferdehirt RR, Kruesi WS, Meyer BJ. 2011. An MLL/COMPASS subunit functions in the C. elegans dosage compensation complex to target $\mathrm{X}$ chromosomes for transcriptional regulation of gene expression. Genes Dev 25: 499-515.

Powell JR, Jow MM, Meyer BJ. 2005. The T-box transcription factor SEA-1 is an autosomal element of the X:A signal that determines C. elegans sex. Dev Cell 9: 339-349.

Privalsky ML. 2004. The role of corepressors in transcriptional regulation by nuclear hormone receptors. Annu Rev Physiol 66: 315-360.

Rhind NR, Miller LM, Kopczynski JB, Meyer BJ. 1995. xol-1 acts as an early switch in the C. elegans male/hermaphrodite decision. Cell 80: 71-82.

Rosenfeld MG, Lunyak VV, Glass CK. 2006. Sensors and signals: A coactivator/corepressor/epigenetic code for integrating signal-dependent programs of transcriptional response. Genes Dev 20: 1405-1428.

Salz HK, Erickson JW. 2010. Sex determination in Drosophila: The view from the top. Fly (Austin) 4: 60-70.

Sefton L, Timmer JR, Zhang Y, Beranger F, Cline TW. 2000. An extracellular activator of the Drosophila JAK/STAT pathway is a sex-determination signal element. Nature 405: 970-973.

Shilo BZ, Haskel-Ittah M, Ben-Zvi D, Schejter ED, Barkai N. 2013. Creating gradients by morphogen shuttling. Trends Genet doi: 10.1016/j.tig.2013.01.001.

Skipper M, Milne CA, Hodgkin J. 1999. Genetic and molecular analysis of $f_{0 x-1}$, a numerator element involved in Caenorhabditis elegans primary sex determination. Genetics 151: 617-631.

Smith DB, Johnson KS. 1988. Single-step purification of polypeptides expressed in Escherichia coli as fusions with glutathione S-transferase. Gene 67: 31-40.

Williams DC, Boulin T, Ruaud AF, Jorgensen EM, Bessereau JL. 2005. Characterization of Mos1-mediated mutagenesis in Caenorhabditis elegans: A method for the rapid identification of mutated genes. Genetics 169: 1779-1785.

Wolfe SA, Nekludova L, Pabo CO. 2000. DNA recognition by Cys2His2 zinc finger proteins. Annu Rev Biophys Biomol Struct 29: 183-212.

Wong CW, Privalsky ML. 1998. Transcriptional repression by the SMRT-mSin3 corepressor: Multiple interactions, multiple mechanisms, and a potential role for TFIIB. Mol Cell Biol 18: $5500-5510$

Yao TP, Ku G, Zhou N, Scully R, Livingston DM. 1996. The nuclear hormone receptor coactivator SRC-1 is a specific target of p300. Proc Natl Acad Sci 93: 10626-10631. 


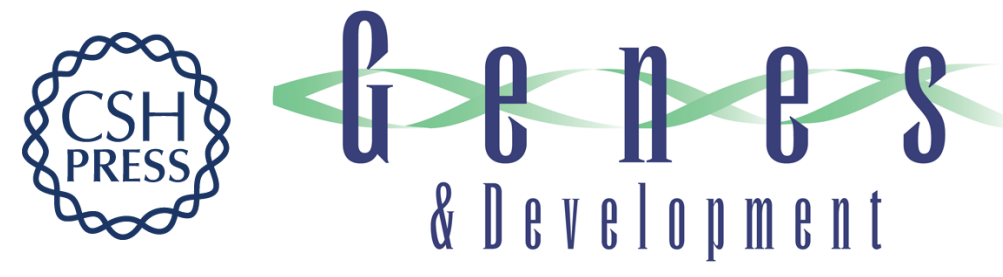

\section{Molecular antagonism between X-chromosome and autosome signals determines nematode sex}

Behnom Farboud, Paola Nix, Margaret M. Jow, et al.

Genes Dev. 2013, 27: originally published online May 10, 2013

Access the most recent version at doi:10.1101/gad.217026.113

\section{Supplemental http://genesdev.cshlp.org/content/suppl/2013/05/02/gad.217026.113.DC1 Material}

References This article cites 64 articles, 33 of which can be accessed free at: http://genesdev.cshlp.org/content/27/10/1159.full.html\#ref-list-1

\section{License}

Email Alerting

Receive free email alerts when new articles cite this article - sign up in the box at the top Service

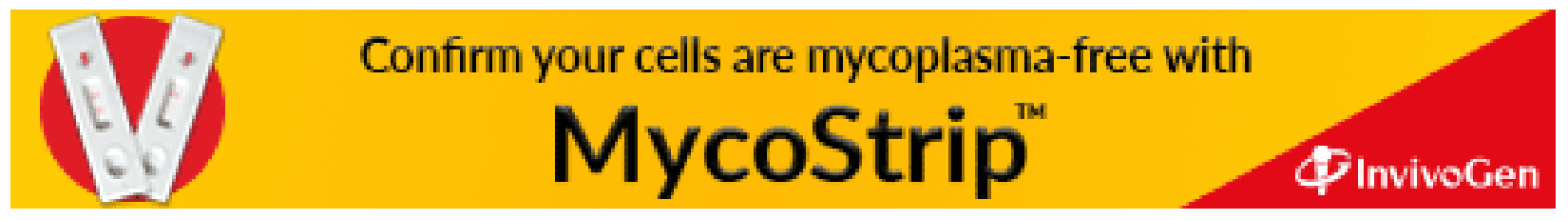

